\title{
Twenty Years of XBRL: What We Know and Where We Are Going
}

\author{
Bartolacci, Francesca $^{1}$; Caputo, Andrea ${ }^{2,3}$; Fradeani, Andrea ${ }^{1}$; Soverchia, Michela ${ }^{1}$ \\ ${ }^{1}$ University of Macerata, Macerata, Italy \\ ${ }^{2}$ University of Trento, Trento, Italy \\ ${ }^{3}$ University of Lincoln, Lincoln, United Kingdom
}

DOI: 10.1108/MEDAR-04-2020-0846

\begin{abstract}
Purpose

This paper extends the knowledge of eXtensible Business Reporting Language (XBRL) to synthesize what twenty years of accounting and business literature on XBRL suggests about the effective improvement from its implementation in financial reporting.

Design/methodology/approach

A systematic literature review and bibliometric analysis of 142 articles resulted in the identification of five primary research streams: adoption issues; financial reporting; decision-making processes, market efficiency and corporate governance; audit and assurance issues; and non-financial reporting.

Findings

The results reveal a scarcity of studies devoted to explicating the consequences of XBRL implementation on financial reporting. Also, some papers' results question the usefulness of the language on the decision-making process. The overall lack of literature concerning the impact of XBRL on financial statement preparers, especially with reference to SMEs, is evident. Moreover, the consequences on corporate governance choices and the relevant internal decision-making processes are rarely debated.

\section{Research limitations/implications}

The findings are useful for users of companies' financial disclosure policies, particularly for regulators who manage XBRL implementation in countries where XBRL has not yet been adopted as well as for others working in specific areas of financial disclosure, such as non-financial reporting and public sector financial reporting.
\end{abstract}

\section{Originality/value}

This study differs from previous literature on XBRL as it focuses on a wider period of analysis and offers a unique methodology - combination of bibliometric and systematic review - as well as a business perspective for deepening XBRL.

\section{Keywords}

XBRL; financial reporting; bibliometric; literature review; decision-making process; VOSViewer

\section{Introduction}

This paper deals with XBRL (eXtensible Business Reporting Language), a markup language derived from the better-known XML (eXtensible Markup Language) and designed to allow "software vendors, programmers, and end users to enhance the creation, exchange, and comparison of business reporting information" (XBRL 2.1 specification). Charles Hoffman, an American certified public 
accountant who started exploring the use of XML in the world of accounting in 1998 (Kernan, 2009), pioneered it. XBRL's development is managed by a global non-profit consortium, XBRL International (Kernan, 2009).

In sum, encoding a document in XBRL means breaking it down, following the language specifications into a finite set of elements collected into an instance document, and containing the facts of the business report; each element is marked with a tag, enclosed in a specified taxonomy - it encompasses the concepts for use in the business report - which can therefore be easily transmitted and processed electronically. Having, for example, an instance document of a financial statement, any XBRL compatible device can easily access its contents - recognizing the latter via the taxonomies utilized for its encoding, that the instance must identify - and use it according to the different instructions provided by the user (Debreceny et al., 2009).

Since twenty years have passed since XBRL was first launched, this language (in its subsequent evolutions) has become the global standard of electronic financial reporting. Disseminated worldwide, XBRL has been adopted by a range of businesses, from listed companies to small and medium-sized enterprises, as well as used for tax returns and regulatory filings, in the private and public sectors. Lastly, the "conquest" of the European Union's regulated markets with the single electronic reporting format (ESEF) mandate: starting from financial years beginning on or after 1 January 2020, issuers must mark up the IFRS consolidated financial statements, contained in their annual financial reports prepared in eXtensible HyperText Markup Language (XHTML) format, using Inline XBRL (iXBRL) ${ }^{1}$.

Specifically, XBRL was developed to significantly improve business reporting to address the challenges of a digital and globalized economy; significant expectations have been placed on the new markup language, especially in terms of improving the accessibility, availability (Baldwin and Trinkle, 2011), administrative burden reduction, and usefulness (Vasarhelyi et al., 2012) of financial data compared to more traditional formats (such as PDF, HTML, DOC or XLS). The U.S. Securities and Exchange Commission (SEC) XBRL mandate in 2009, by the Rule No. 33-9002, is deemed as one of the most important enhancements in the disclosure environment within the first decade of the $21^{\text {st }}$ century (Debreceny et al., 2011). Have all expected improvements effectively taken place? This study tries to shed light on the real impacts of tagged information since the associated taxonomy has attained a greater maturity level.

The literature about XBRL is vast and has constantly grown over the last twenty years; it includes both academic and operational studies dedicated to practitioners. As a multidisciplinary concept, XBRL is investigated from different points of view: as a new language for corporate financial reporting but also as a technological innovation, as an opportunity for shareholders or as a new educational topic.

In light of the above, this paper aims to deepen knowledge of XBRL from a business perspective and to understand whether and how scientific literature verifies the effective impacts of this new language on financial reporting, as well as to examine if the benefits expected at the beginning of the millennium have been effectively achieved.

To achieve this objectives, we performed a bibliometric analysis and a systematic literature review of 142 articles published between 2001 and 2019 to ensure scientific rigor in mapping the knowledge produced so far about XBRL and its impact on financial reporting. Our analysis was conducted with the aid of the bibliometric method of visualization of similarities, through bibliographic coupling, that resulted in the identification of five primary streams of research: the first theme focuses on XBRL adoption issues (cluster 1); the second theme pertains to financial reporting stricto sensu (cluster 2); the third theme is related to decision making processes, market efficiency, and corporate governance

\footnotetext{
${ }^{1}$ For the specific details on the ESEF mandate, also with reference to the limits and the conditions of iXBRL adoption, refer to the European Parliament and of the Council and the Commission Delegated Regulation (EU) 2019/815.
} 
(cluster 3); the fourth theme concerns audit and assurance issues (cluster 4); and the fifth theme regards non-financial reporting (cluster 5).

Our study differs from previous literature on XBRL (Roohani et al., 2010; Liu, 2013; Perdana et al., 2015) as it encompasses a wider period of analysis and utilizes a unique methodology, combining bibliometric and systematic literature review from a business perspective. Furthermore, this paper tries to surpass previous analyses aimed to detect the levels of awareness and an overall understanding of XBRL (Nel and Steenkamp, 2008; Buys, 2008) to determine if and how XBRL has effectively improved financial reporting. In the next sections, we explain the methods adopted, present their results, and then provide a literature review of the identified thematic clusters to suggest future research avenues and develop conclusions.

\section{Methodology}

To provide a comprehensive map of the knowledge structure of the field of study investigating XBRL and to maintain consistency with recent best practices in bibliometric research, we used both a bibliometric analysis and a systematic literature review (Caputo et al., 2018; Dabić et al., 2019). The use of these two complementary methods allows researchers to investigate a topic in depth through the systematic review, while maintaining a wider picture of the evolution of knowledge through a bibliometric analysis.

Aligned with the systematic review method (Tranfield, Denyer and Smart, 2003; Thorpe et al., 2005), a panel of experts was formed to define the field of research, choose keywords, select the database, and articulate the set of inclusion and exclusion criteria. We performed a systematic search through the database Scopus during the month of July 2019 with the criteria detailed further. The maximum time limit allowed by the database was chosen to avoid distortion of the results, and it was found that the first article was published in 2001 and the last in 2019. This is coherent with the fact that on July 31, 2000, XBRL International published the XBRL 1.0 specification and its first taxonomy for financial reporting, according to U.S. GAAP (Kernan, 2009). The use of the Scopus (Business, Management and Accounting) database, rather than a set of relevant journals, was chosen to avoid potential bias and/or omission in the final set of selected articles, allowing us to consider all the possible works published in a wider range of journals. Consistent with best practices in bibliometric research (Caputo et al., 2018), a cross-validation was made with the Web of Science and EBSCO Business Premier that ensured the inclusion of all relevant data.

The search for data in Scopus was performed with the keywords "XBRL" OR "eXtensible Business Reporting Language" present in the title, abstract, or keyword fields to ensure the comprehensive nature of our search. Regarding the language of publication, consistent with the best practices in systematic review studies and the nature of our search, English was chosen as the search language. We selected only articles published in peer-reviewed journals in the dataset as these articles are the source of the most updated knowledge. Through these search criteria, we retrieved an initial sample of 204 documents. This sample size was consistent with other bibliometric studies with similar samples (Caputo et al., 2018; Sassetti et al., 2018), confirming its suitability.

Given that publications about XBRL are multidisciplinary and may have practical, rather than theoretical, relevance, we undertook a filtering process to ensure adherence with our research question, consisting of independent reading of abstracts by three of the authors. To maintain inclusiveness and limit human error, we then matched resulting records and settled disagreements through panel discussions. This resulted in a final sample of 142 articles. To arrive at this number of articles, we established and applied several criteria. The first criteria verified the main object of the paper had to be XBRL; according to this criteria, we excluded some papers where a discussion of XBRL was present but was marginal to the paper's research design and objective. Next, we targeted the coherence of the articles with respect to our research objective. As already specified, XBRL is an extremely broad concept that can be approached from different disciplines and perspectives. According to our research 
aim, we are interested in studying XBRL as a tool that impacts companies' financial reporting and, in more general terms, aspects/elements concerning business economics, such as adoption issues, audit and assurance implications, decision-making processes, and corporate governance. In a highly synthetic way, we attempted to understand the impact of XBRL on internal and external economic decision processes. Thus, we excluded articles that did not address the above-mentioned aspects, such as a few papers which focused on educational or technological aspects and features of this language. We then made adjustments for the errors and inconsistencies in the final database; for example, homogenizing the authors' keyword spelling.

We then used the final dataset of 142 articles as a basis for both bibliometric analysis and a qualitative systematic literature review to map knowledge of the field. For the purpose of the review, each article was fully read and analyzed qualitatively, consistent with best practices in systematic literature reviews (Pittaway and Cope, 2007; Barclay et al., 2011). Each article was coded, tagged, and later grouped into clusters (Tranfield, Denyer and Smart, 2003; Thorpe et al., 2005). The process was dynamic, allowing new tags for inclusion during the process of reading articles to achieve flexibility in categorizing information and reducing biases that may arise from a rigidly pre-set system Dabić $e t$ al., 2019; Bartolacci et al., 2020).

Bibliometrics is defined as a part of scientometrics that applies statistical methods to the study of scientific activity in a field of research (Zupic and Čater, 2015). Bibliometrics combines two main procedures: performance analysis and science mapping. Performance analysis is based on activity indicators, which provide data about the volume and impact of research through the use of a wide range of techniques, including word frequency analysis, citation analysis, and counting publications by unit of analysis (e.g., authorship, country, affiliation, etc.). Science Mapping is based on first and secondgeneration relation indicators which deliver spatial representations of how different scientific elements are related to one another. The objective of science mapping is to show the structural and dynamic organization of knowledge in a certain field of research. To overcome limitations that pertain to every synthetic indicator, prior studies argued for the use of more than one indicator (Marzi et al., 2017). Therefore, we have performed simultaneous analyses based on alternative bibliometric techniques used in a complementary fashion. Particularly, we chose to use the indicators of co-citation, bibliographic coupling, and co-occurrence of keywords analysis. Co-citation analysis promotes an investigation when two articles are both independently cited by one or more articles. Bibliographic coupling is when two articles cite a common third article, indicating that a probability exists that the two articles discuss a common topic. Co-occurrence of keywords uses the author's provided keywords to investigate the conceptual structure of a field. The result is a comprehensive picture of the most important knowledge about XBRL, which is derived by systematizing the results from the separate analyses. We then developed clusters of concepts based on the keyword analysis and reviewed the most important papers from each cluster as identified by the complex web of bibliometric analyses performed.

With regard to the tools used for the calculation of these indicators, we used the software program VOSViewer (van Eck and Waltman, 2010). The graphs resulting from the analyses represent a network of elements in which the size of the circle varies according to the importance of the element, while the network connections represent the closeness of the link between elements. The spatial position of the circles and the different colors were used to cluster the items. For a detailed explanation of the scripts and mathematical algorithms adopted in VOSViewer, please see van Eck and Waltman $(2007 ; 2010)$.

\section{Results of bibliometric analysis}

\subsection{Activity indicators}

The first indicator shows the evolution of the field in terms of volume of scientific production counted by the number of published articles in the dataset. Figure 1 indicates the study of XBRL as a relatively recent field where three temporal stages can be identified. The early stages (2001-2008) are characterized by unsteady production, averaging 1.5 articles per year. The growth stage (2009-2011) is 
illustrated by a significant increase in scientific production (average 10 articles per year) that culminated in 17 articles published in 2011. The maturity stage (2012-2018) is where scientific production stabilized at an average of 13 articles published per year, a number that will probably manifest also in 2019 , where data for half of the year already shows nine publications.

\section{Please insert Figure 1 - publication by year}

The average number of citations for an article was 18.24 (S.D. 27.72), the median was nine, the mode two ${ }^{2}$. Sixty-two journals published articles in the dataset, and the average number of citations per journal was 42.14 (S.D. 78.49), while the median was 14 and the mode two. These numbers confirm how research on XBRL is impacting the field, despite XBRL being a niche in management and accounting literature. Table 1 shows data from the 33 journals in the dataset that had at least 10 citations.

\section{Please insert Table 1 - Journals with at least 10 citations}

Additionally, we investigated the rank of the journals with regard to the performance indicators of the journals where XBRL research is published. To do so, we adopted the Australian Business Deans Council Journal list (ABDC, available at www.abdc.edu.au) that exhibits the widest number of journals. Table 2 depicts how most of the research on XBRL is published in very important journals, ranked A* or A, confirming our insight that the field is impactful and has reached maturity in its scientific dissemination.

\section{Please insert Table 2 - Publications by rank}

Assessing the country where the corresponding author's affiliation is based (Table 3), of 23 countries, three produced $66 \%$ of the total research on XBRL, and those are the United States, Australia, and Canada.

\section{Please insert Table 3 - Countries by publication}

Please insert Table 4 - Most cited articles

The dataset comprised 281 authors for the 142 publications. From these, only 22 authors had authored at least three publications, as shown in Table 5.

Please insert Table 5 - Most prolific authors

\subsection{Co-citation analysis}

A co-citation analysis occurs when the same articles are cited by several other articles. This measure is seen as an indication that the content of the co-citing articles is related in a meaningful way. This subsection presents co-citation analyses of articles, journals, and authors.

\section{Articles}

When analyzing the 142 articles included in our dataset, and a minimum threshold of five citations for a cited reference is considered, the set obtained contains 47 cited references of the 7,146 total cited references. To further understand of this indicator, network and density diagrams are presented in Figures 2 and 3. The five most connected references are: Debreceny et al. (2010), Plumlee and Plumlee (2008), Hodge et al. (2004), Boritz and No (2009), and Premuroso and Bhattacharya (2008).

\footnotetext{
${ }^{2}$ In calculating these metrics, the nine articles published in 2019 were removed by the dataset since they did not include citations (at the time of writing, full citation data is not yet available for the year 2019).
} 


\section{Journals}

Concerning the 2,687 cited sources, 22 journals received more than 40 citations. The five journals with the highest numbers of citations reflect: Journal of Information Systems (293), The Accounting Review (292), International Journal of Accounting Information Systems (204), Journal of Accounting Research (197), and Journal of Accounting and Public Policy (140). Figures 4 and 5 present the network and density diagrams of the co-citation analysis of journals. As noted from the co-citation analysis, the Journal of Information Systems and The Accounting Review are the most active and influential journals in the study of XBRL.

Please insert Figure 4 - Network diagram of the largest connected set of cited sources

Please insert Figure 5 - Density diagram of the largest connected set of cited sources

Authors

When investigating the co-citation analysis of authorship of the 6,033 cited authors, only 41 had been cited more than 40 times. The authors with the highest number of citations include Debreceny, R. (171 citations), No, W.G. (152 citations), Vasarhelyi, M.A. (129 citations), Piechocki, M. (133 citations), Felden, C. (111 citations), Pinsker, R. (100 citations), and Boritz, J.E. (99 citations). Figures 6 and 7 illustrate the network and density diagrams of the co-citation analysis of authors, demonstrating how these authors are not only the most cited but also the most connected according to the co-citation analysis.

Please insert Figure 6 - Density diagram of the largest connected set of cited authors

Please insert Figure 7 - Network diagram of the largest connected set of cited sources

\subsection{Bibliographic coupling}

Bibliographic coupling analyzes the extent to which two articles are related by referencing the other same article. This subsection presents bibliographic coupling analyses of articles, journals, and authors in our dataset.

\section{Articles}

Bibliographic coupling of the 142 articles in our dataset is helpful to better understand the theoretical foundations of the publications included in the sample. We analyzed the network of articles referenced to show that the largest set of connected documents contains 106 publications $(74.64 \%$ of the dataset), confirming the existence of an integrated XBRL field of study. The five studies with highest indices of bibliographic coupling are Perdana et al. (2015), Liu (2013), Valentinetti et al. (2012, 2013), and Birt et al. (2017).

To complement the analysis of this indicator, network and density diagrams are presented in Figures 8 and 9, where the works of Perdana et al. (2015) and Liu (2013) can be considered as focal papers in the field of XBRL.

Please insert Figure 8 - Network diagram of the bibliographic coupling of articles

Please insert Figure 9 - Density diagram of the bibliographic coupling of articles 


\section{Journals}

With regards to the bibliographic coupling analysis of journals, we set a minimum threshold of two articles per journal (Ferreira, 2018), resulting in a subset of 20 journals of 65 . Our analysis reveals that the five journals with the highest bibliographic coupling index are Journal of Information Systems, International Journal of Accounting Information Systems, International Journal of Digital Accounting Research, Journal of Emerging Technologies in Accounting, and International Journal of Accounting and Information Management.

To complement the analysis of this indicator, network and density diagrams are presented in Figures 10 and 11, through which Journal of Information Systems and International Journal of Accounting Information Systems can be classified as the focal journals in the field of XBRL.

Please insert Figure 10 - Network diagram of the bibliographic coupling of journals

Please insert Figure 11 - Density diagram of the bibliographic coupling of journals

Authors

As far as the co-citation analysis of authorship, of the 281 authors in our dataset, only 69 had published at least two papers on XBRL. The five authors with the highest bibliographic coupling index are, respectively Liu C., Valentinetti D., Rea M.A., No W.G. and O'Farrell G. Figures 12 and 13 present the network and density diagrams of the bibliographic coupling analysis of authors, confirming how all the authors in the field of XBRL are connected with each other and validating the homogeneity of the field.

Please insert Figure 12 - Network diagram of the bibliographic coupling of authors

Please insert Figure 13 - Density diagram of the bibliographic coupling of authors

\subsection{Keywords analysis}

Analysis of the co-occurrence of keywords is based on the principle that a research specialty can be identified by the particular associations established between its keywords (López-Fernández, Serrano-Bedia and Pérez-Pérez, 2016). While the first and second-generation indicators based on the analysis of citations involve an intrinsic bias toward older studies, the analysis of the co-occurrence of keywords does not suffer from this limitation, thus allowing important recent works to emerge. Given that XBRL is a contemporary field that is subject to fast-paced technological change, we agreed to complement the analysis of citations with the analysis of co-occurrence to identify the research's main topics and trends.

To perform the keyword analysis, we first extracted the authors' keywords from each article in our dataset. These keywords were then filtered for duplicates and homogenized in terms of spelling; then, only unique values were used for analysis (Dabić et al., 2019). Similar to the citation analyses, the resulting data was then analyzed with VOSViewer's tool for analyzing the co-occurrence of terms, in our case, the keywords. Only keywords that occurred at least two times were kept, resulting in 84 of 146 keywords to constitute the largest set of connected terms.

The five most frequently occurring keywords are XBRL (128 occurrences), financial reporting (36 occurrences), corporate governance (11 occurrences), disclosure (9 occurrences), and voluntary disclosure ( 9 occurrences). These five keywords comprise $39.46 \%$ of the total occurrences of keywords, showing the diversity of topics investigated in XBRL (Figure 14). 
To complement our analysis of co-occurrence of keywords, the network of co-occurrence links between these keywords is presented through the diagrams of the network and density of keywords (FIGURE). This analysis suggests how XBRL appears as the central and focal node of the field, with five clusters of connected topics emerging with it.

Please insert Figure 15 - Network diagram of the co-occurrence of keywords

Please insert Figure 16 - Density diagram of the co-occurrence of keywords

\section{Results of the Systematic Literature Review}

\subsection{Cluster "Adoption issues"}

This cluster is composed of 31 articles published from 2001 to 2019; the majority (22 articles) were published in the second decade of the above-mentioned period. This is explained by the fact that they concern issues related to the concrete implementation of XBRL in different contexts and countries, albeit addressed in different ways. Often these articles examine the so-called XBRL "first time adoption" both at the macro level, focusing on the whole process (Felden, 2011; Farewell et al., 2017), and at the micro level where they analyze more specific aspects, such as the adopted taxonomies (Piechocki et al., 2009; Valentinetti and Rea, 2013; Fradeani et al., 2016).

Several articles adopt a theoretical approach; those that do concentrate pm the first part of the analyzed period and are mainly devoted to describing the XBRL operating features and potential benefits that could derive from its adoption through qualitative and descriptive analysis (Cohen, 2004; Locke and Lowe, 2007; Bonsón et al., 2007). Instead, most articles employ an empirical approach, using both qualitative and quantitative methods; this is consistent with the object of the cluster that focuses on operational processes of XBRL adoption.

Some papers focus their attention on the motivations that push towards the adoption of XBRL, making forecasts of impacts and advantages. Most articles are exploratory and utilize a qualitative research approach, conducting surveys with the use of interviews to capture motivations. This is the case for Escobar-Rodríguez and Gago-Rodríguez (2012) who conduct an analysis of the reasons why pioneers supported the introduction of XBRL from its earliest days in Spain; their initial engagement was based more on intuition than on in-depth knowledge of the technological advantages gained from its application. Pinsker and Felden (2016) also focus on motivations; they examine the German case, in particular the voluntary adoption intent combining technology framing theory, institutional theory, and the professional role literature. Results indicate that professional role and normative pressure (i.e. social networks) yield positive relationships with XBRL adoption intent.

Several papers study the characteristics of the early adopters, such as the voluntary XBRL adopters using the SEC voluntary filing program. Callaghan and Nehmer (2009) compare a sample of voluntary adopters to pair-matched companies to determine the existence of systematic differences between voluntary filers and their control sample counterparts. They find that early adopters are larger-sized, less financially leveraged, and have lower corporate governance ratings than those of the control group. However, Boritz and Timoshenko (2015) examine the same kind of early American adopters and identify three different explanatory factors: a higher propensity to voluntarily disclose information, stronger corporate governance, and higher profitability. Also with reference to the United States, Ragothaman (2012) analyzes the financial characteristics of voluntary adopters of XBRL and the relationship between firm key financial and accounting variables and voluntary XBRL adopters. His results indicate that plant intensity, growth, and complexity are useful in discriminating voluntary "XBRL adopters" from non-adopters. 
Comparative analysis in this cluster is lacking. Only Troshani et al. (2018) adopt a comparative approach to analyze qualitative evidence from the Netherlands, the United Kingdom, and Australia to understand how digital reporting is established to reduce administrative burden without compromising regulation effectiveness. Comparative analysis of XBRL adoption in different countries should be promoted as it could provide a better understanding of how XBRL is actually used by regulators in different contexts and why some countries have opted to make it mandatory.

Another unexplored theme is the impact of XBRL adoption on companies' financial performance. Only one article (Jackson and Kwansa, 2011) mentions this topic, albeit in a rather marginal way. Future research examining the relationship between early adopters and financial performance in countries in which XBRL is not mandatory could deliver beneficial information to help better understand the phenomenon. Additionally, studies should be conducted to identify characteristics and key factors of the adoption processes that produce better impacts on different types of XBRL users.

Finally, no paper deals with XBRL adoption by public entities, despite the fact that XBRL has become mandatory in several countries for this type of organizations (such as in Italy for example). Future research should explore the public sector in order to understand comparability, as well as if administrative burden reduction can be achieved.

Considering our research aim, the papers of this cluster dealing with different adoption issues do not offer a significant contribution because they do not extend the effects produced by the described programs of XBRL implementation.

\subsection{Cluster "Financial reporting"}

The cluster consists of 39 articles: the first one was published in 2004 and the last one in 2019; as many as 31 were published after 2010 .

The very first papers focus on the introduction of XBRL. Doolin and Troshani (2004) provide basic information on XBRL and how it works; they discuss its stakeholders from production to consumption and suggest a tentative research agenda. Debate on the characteristics and potential of the new language also takes place outside the United States; Richards and Tower (2004) offer an Australian perspective; Apostolou and Nanopoulos (2009) discuss XBRL with an overview of the global markets and Europe. Gray and Miller (2009) research the main accounting, financial reporting, and internal audit concerns of organizations to identify XBRL's usefulness.

On January 30, 2009, the SEC issued the final rule Release No. 33-9002 which mandates interactive data using XBRL format. The U.S. securities markets, the most important in the world, thus became the preferred research field to investigate the impacts of this language derived from XML on financial reporting.

Debreceny et al. (2010) initiate the research on the quality of XBRL filings. They focus on the correctness of mathematical relationships between the data filed to the SEC; a significant number of instances had errors, nearly half due to sign flips. Referring to the SEC's XBRL voluntary filing program (VFP) and not limited to mathematical relationships, Bartley et al. (2011) find a high frequency of errors in XBRL filings, decreasing strongly over time, thus suggesting the success of VFP. Similarly, with reference to the first six quarters of the SEC's XBRL mandate. Du et al. (2013) note a considerable number of errors but observe their significant reduction over time as a consequence of learning by doing of filers.

Research on the quality of XBRL then addresses the extensions. Although the U.S. GAAP taxonomy contains a vast number of elements, filers can create custom elements if the existing ones do not fit: a feature to guarantee financial reporting completeness but also a risk for comparability. With reference to monetary extensions, Debreceny et al. (2011) find that $12 \%$ of facts that reference monetary elements rely on extensions and $40 \%$ of these were not necessary. Li and Nwaeze (2015) study the association between extensions and firms' financial information environments; in the early years of 
XBRL adoption, they label this association as negative but, in the later phase, it becomes positive, supporting the SEC's choice to allow them.

Studies on extensions are part of the more general key theme of the consequences of XBRL adoption on standardization and comparability of financial reporting. Vasarhelyi et al. (2012) discuss XBRL potential from a theoretical perspective,- thanks to effects of its standardization on financial statement data - to improve its usefulness. In the initial years of the SEC's XBRL mandate, however, Dhole et al. (2015) highlight a decline in financial reporting comparability and assert how it is larger for firms that use more extensions and lower in case of financial statements subject to greater accounting discretion. Scherr and Ditter (2017) investigate the factors associated with XBRL customization for a large sample of 10-K filings to the SEC between 2009 and 2013. They conclude that the reach of the extensions is positively influenced by the level of reporting behavior deviation from common reporting as well as the extent of (voluntary) disclosure, that it is negatively influenced by the extent of firm's involvement and experience with XBRL filing process. On issues of comparability, with particular reference to the use of non-standard elements, Euto et al. (2017) develop the Financial Concept Element Mapper (FinCEM), a fully automated framework - based on the hierarchical information within the XBRL calculation linkbase - which can contribute towards a better XBRL interoperability; on interoperability issues, see also $\mathrm{Zhu}$ and $\mathrm{Wu}$ (2011).

Another line of research concerns the impact of the XBRL mandate on the timeliness of financial reporting. As far as 10-K and 10-Q filings from 2007 to 2014, $\mathrm{Du}$ and $\mathrm{Wu}$ (2018) posit that the SEC's XBRL mandate improves the timeliness, by one or two days, only for large accelerated and accelerated filers; they observe no impact among smaller ones. Similar results are documented by Zhou (2019); with reference to 10-K filings from 2007 to 2016, the lag decreases for both categories of accelerated filers but significantly increases for smaller reporting firms (with considerable growth of the probability of late filing). Zhou also uncovers that delay is greater in the cases of more complex XBRL filings and can be mitigated by a service provider with more XBRL filing experience. For more on XBRL as a tool to improve the timeliness of local government reporting, see Sohl et al. (2018).

Furthermore, there are two additional papers of particular interest. The first one deals with iXBRL, «a standard for embedding XBRL fragments into an HTML document» (Inline XBRL Part 1: Specification 1.1) recently adopted by both the SEC (see Release No. 33-10514) and the European Union (Commission Delegated Regulation (EU) 2018/815). Basoglu and White (2015) discuss its possible use versus traditional XBRL in the context of the SEC's mandate, thus highlighting the potential of the new standard to improve transparency, reduce common encoding errors, and provide assurance. In a second notable paper, Blankespoor (2019) investigates the effects of changes in information processing costs of market participants on firm disclosure; the study provides evidence that firms increased quantitative disclosure in their footnotes after the SEC required their XBRL detailed tagging in response to an expected reduction of financial reporting users' information processing costs.

Beyond the U.S. contextualized papers, the first two refer to the potential use of XBRL under the IFRS. Bonsón et al. (2009) investigate the ability of the then IFRS-GP Taxonomy to adequately cover the reporting practices of the European companies, while Valentinetti and Rea (2012) explore the same issue but with reference to the Italian companies and the most recent IFRS taxonomy. Both studies highlight the inability of taxonomies to adequately cover reporting practices in Europe and in Italy respectively. Moreover, Valentinetti and Rea (2012) suggest the possibility of allowing taxonomy extensions. The last paper deals with determinants of voluntary disclosure in the context of the XBRL mandate (on this topic in the SEC, see Kaya, 2014) but with reference to Italian SMEs: given that Italian taxonomy extensions are not allowed (but a certain margin of flexibility can be obtained using XHTML in the textual fields present in the note). Panizzolo et al. (2017) reveal that the filing software adopted explains the offer of more information than required by Italian law.

First, it is important to highlight how the reviewed literature is polarized on the SEC's XBRL mandate experience; given its worldwide diffusion, it is necessary to better understand the effects of $\mathrm{XBRL}$ on financial reporting in other jurisdictions, under different accounting standards (mainly, but 
not only, the IFRS), with reference to SMEs and users of financial data beyond stock exchange investors (e.g. banks and tax agencies). Scholars should deepen the research on the implications of XBRL on quality and comparability of financial statements, in light of iXBRL, as well as how its adoption impacts preparers (for example, there is much to be said about the role of XBRL-capable accounting software and the possible conditioning of taxonomies in terms of the content and extent of disclosure, especially in the SME context). Finally, this topic warrants more studies on the role of XBRL in the financial reporting of particular industry sectors such as insurance and banking.

\subsection{Cluster "Decision making / market efficiency / corporate governance"}

As most of the articles were published after 2010, this cluster, comprised of 49 articles, can be considered a representation of the maturity of the XBRL research field. Many articles address the effects of mandatory adoption of XBRL, observing improvements in terms of transparency and accessibility of financial reporting information, especially for analysts and investors when making accurate financial performance forecasts. Among these, Hodge et al., 2004 provide the longest-running article in the cluster and the most cited in this literature review; it exemplified one of the first articles to highlight the potentialities of XBRL. Through an experimental setting, the authors infer that XBRL helps nonprofessional investors acquire and integrate financial statements when making investment decisions. Some years later, other studies highlight that XBRL can reduce information processing costs and strengthen the transparency of capital markets (Zhang et al., 2019) while supporting financial statements' users in judgments and decisions (Ahmadpour 2011). Nonetheless, regulators should limit customized tags to avoid forecast errors and the dispersion of information (Felo et al., 2018).

Given the high cost of developing and implementing XBRL, it is crucial to assess the influences, in terms of costs and benefits, before its adoption on a large scale. Accordingly, Kim et al. (2012) cite an increase in information efficiency and a decrease of risk and information asymmetry. Chen et al. (2018) also provide evidence for firms with less accessible data of higher information asymmetry, greater information processing costs, and lower financial reporting transparency. Liu et al. (2014 Journal of Accounting and Public Policy) and Ly (2012) suggest that the mandatory use of XBRL increases the number of analysts and creates benefits, regardless of errors found and concerns raised in early stages of adoption.

Concerning information accessibility, some authors question if XBRL may reduce asymmetries among investors. They highlight that the answer often depends on a firm's size (Blankespoor et al., 2014 and Geiger et al., 2014), but not in the sense the SEC anticipated: smaller investors should have had fewer information barriers (SEC 2009). In fact, Efendi et al. (2014) detect limited evidence that XBRL benefits small investors in terms of more market efficiency. Yoon et al. (2011) and Liu et al. (2017) verify a strong negative relationship between XBRL adoption and information asymmetry for large-sized firms. Nevertheless, post-XBRL regulation, small institutions' trading responsiveness - in terms of stock-picking skills - increases more compared to large institutions (Bhattacharya et al., 2018).

Other authors expand the research focus for increasing the aspects under observation. Arnold et al. (2012) verify that tagging the qualitative information of an annual report has important effects for investors in their predictions of company risk and stock price, which benefit from a more comprehensive analysis. This has important implications in light of the regulators' decision to preclude inclusion of the "Management's Discussion and Analysis" information in XBRL mandatory tags.

Further authors analyze the impacts of using XBRL to support investment decisions, observing technological aspects that may influence the perceived usefulness or ease of use (Janvrin et al., 2013; Yen and Wang, 2015). Lambert et al. (2019) do not find a significant change in forecast accuracy postXBRL but instead highlight more frequent analyst forecast announcements. Regarding possible causes of missing improvements, Locke et al. (2015) observe that different accounting methods employed by companies make ratios generated automatically by the software incomparable. Chowdhuri et al. (2014) verify this semantic heterogeneity as a fundamental issue of XBRL interoperability. 
Another aspect under observation in this cluster concerns the economic consequences of XBRL adoption for shareholders. Hao et al. (2014) and Chen et al. (2015) show that the cost of equity capital is significantly and negatively associated with XBRL voluntary filing. However, Liu et al. (2014 Decision support system) confirm the transaction cost theory predictions, due to the uncertainty related to the unproven technology increases transaction costs and the cost of capital in China during the early adoption period. Other researchers focus on the impact of structured data in loan contracting. Kaya and Pronobis (2016) and Lai et al. (2015) find that technology advancements such as XBRL adoption lead to a lower cost of debt for firms.

Studies of the incidence of XBRL for market participants are numerous, but little is known about the mechanisms underlying the real impact of the markup language on internal decision-making processes and thus on corporate governance. In this context, Roohani et al. (2009) argue that XBRL can support a comprehensive corporate governance system, facilitating the delivery of information and reports to internal as well as external users. Moreover, Premuroso and Bhattacharya (2008) claim that superior corporate governance is associated with a firm's decision to be an early filer of financial information in XBRL. Cormier et al. (2019) observe that good corporate governance is positively associated with XBRL extensions and verify its relationship with financial performance. Finally, XBRL has the potential to improve governance if those advocating XBRL understand the value chain of information of governance players and establish the role of XBRL in driving better governance decisions (Alles and Piechocki, 2012).

In sum, the findings of the articles of this cluster are overall mixed, while highlighting some improvements of the accessibility and usability from financial statement information. The obtained empirical results depend on the observed firms' features; thus, it is difficult to draw a uniform conclusion.

\subsection{Cluster "Audit and assurance"}

The cluster consists of 12 articles: the first one was published in 2001 and the last one in 2018 (only 3 are before 2010). After separating the papers for introductory purpose and those about accountants' and auditors' awareness (see, for all, Pinsker, 2003), we can identify two main lines of research.

The first one highlights the assurance of XBRL-related documents: Srivastava and Kogan (2010) develop a framework of assertions for validating XBRL instance document filed with the SEC; Boritz and No (2016) propose audit objectives, tasks, and computer-assisted functions for the same goal (but applicable, according to the authors, also in other countries); Alles and Gray (2012) develop a framework related to the demand for external XBRL assurance and based on relative cost comparisons.

The second line of research concerns the consequences of XBRL adoption on audit fees. Shan et al. (2015) and Shan and Troshani (2016) advocate how XBRL adoption reduces auditing fees with reference, respectively, to the U.S. (NYSE and NASDAQ), Japan (TSE), and China (Shanghai Stock Exchange); Amin at al. (2018) present similar conclusions, while studying the auditing report lags with reference to a sample of 1.351 S\&P clients observed from 2007 to 2013.

The audit and assurance issues must be better studied, particularly outside the SEC's XBRL mandate and with reference to unlisted companies, too. The already mentioned diffusion of the iXBRL standard is also particularly imperative. The ESEF adoption by the EU will represent a further stimulus to research, especially (and differently from the SEC's mandate) if explicit forms of assurance are required.

\subsection{Cluster "Non-financial reporting"}

This cluster is comprised of seven articles published in the second decade of the analyzed period. All papers deal with the use of XBRL within the wider world of non-financial reporting. Considering that XBRL seems to offer many advantages and has become mandatory for financial reporting in many countries, these articles propose an extension of XBRL implementation to this kind of corporate 
reporting. In brief, these articles infer that XBRL offers the opportunity to develop more rigorous nonfinancial reporting, increase, comparability, and reduce costs.

Non-financial reporting is a heterogeneous and increasingly relevant field. Several papers focus their attention on sustainability reporting (Seele, 2016 and 2017), while others emphasize environmental reporting (Muñoz et al., 2018; Satoh, 2011). These types of corporate reporting present shortcomings as they are not mandatory: companies are involved only on a voluntary basis and do not use standardized formats (Knebel and Seele, 2015). The advantages of using XBRL are the same as those highlighted for financial reporting: the opportunity to develop rigorous sustainability metrics that increase comparability and reduce costs; more accurate and reliable data management and real-time reporting to internal and external stakeholders. In particular, managers can be better informed and access faster decision-making on financial and non-financial issues. In brief, XBRL taxonomies for sustainability data can contribute to the overall sustainability of societies (Seele, 2016), overcome shortcomings, and foster more transparency, credibility, and comparability of non-financial disclosure (Knebel and Seele, 2015).

Particular attention is devoted to Integrated Reporting, also with the proposal of ad-hoc taxonomies (Gonzalbez and Rodriguez, 2012; La Torre et al., 2018); in this case, XBRL could be a tool to combine financial information with environmental and social data and highlighting their links.

In only one case (Satoh, 2011) the author hones the impact of environmental issues on corporate financial position, stating that a standardized reporting format for gas emissions is critical for reliable analysis of their impact on finances. Accordingly, the paper provides a preliminary XBRL taxonomy for emissions reporting that combines financial and emissions reports.

In several papers, the object of the analysis expands from reporting to include wider corporate planning and control systems. Muñoz et al. (2018) highlight the main internal and external advantages of merging XBRL with environmental reporting (Eco-Management and Audit Scheme - EMAS report) and assert that XBRL can be a useful tool to integrate EMAS issues into the firm's main control system. This could lead to a more coherent business strategy, thanks to the integration of EMAS information into the main company's control system. Additionally, Seele (2017) proposes a wider analysis, in which XBRL serves an instrument to contribute to the "predictive sustainability control" of analytical techniques to identify subjects for mutual deliberation, supervision, and intervention with the goal of preventing future harm related to environmental, social, and governance issues.

As interest in non-financial reporting grows worldwide, and considering that this information should be combined with financial information, the use of XBRL within this "combination" is a topic that should be widely investigated in the future. The various kinds of sustainability reporting (environmental, social, etc.) require standards to allow companies and investors to access comparable and reliable information across national borders, to account for international business and risks, and to avoid the greenwashing phenomenon as well.

Due to the fact that the non-financial reporting issues are quite recent, all analyzed studies focus on potential benefits derived from XBRL implementation in such an area, while there is a lack of studies to verify real and effective impacts.

\section{Conclusion}

This paper aims to extend the knowledge of XBRL from a business perspective and to understand whether and how academic literature has verified the effective impacts of this markup language on financial reporting. Additionally, this analysis investigates if the benefits described by articles published at the beginning of the millennium have been effectively achieved.

The paper assesses this topic through a systematic literature review of 142 articles published in the last twenty years (three of which are literature reviews, so they are not included in our discussion of the 
five clusters). The analysis was enriched with the aid of the bibliometric method of visualization of similarities and through bibliographic coupling; these resulted in the identification of five main research streams: XBRL adoption issues; financial reporting; decision making processes, market efficiency and corporate governance; audit and assurance issues; and non-financial reporting. The most relevant topics and findings are analyzed and also the open questions are outlined (as shown in the following table).

In brief, XBRL exemplifies a topic extensively addressed in the literature, but few studies are devoted to deepening the consequences of its implementation on financial reporting from a business perspective, especially outside the SEC's XBRL mandate and listed companies' contexts. Also, some papers reveal conflicting results on the usefulness of the markup language on the decision-making process.

The additional benefits of an easier electronic exchange of standardized business and financial information are often limited to larger firms rather than smaller ones. This highlights the importance of identifying the technological supports to take advantage of data standardization for smaller firms. Moreover, although the keyword "corporate governance" is prevalent in the articles analyzed, this topic is not adequately investigated, as the impacts of XBRL on corporate governance choices and the relevant internal decision-making processes are scarcely debated.

Another lack of business literature concerns the impact of XBRL on financial statement preparers, especially with reference to SMEs. Are they influenced, for example, by taxonomies in terms of content and extent of disclosure? What are the effects on preparing financial statements with the features and limits of XBRL-capable accounting software used? Another topic that deserves further study, and that will certainly attract the scholars' interest, is the XBRL assurance, especially considering the diffusion of iXBRL.

A systematic representation of the unexplored issues that emerge from the overall analysis is summarized in the next table that contains the main topics and future research developments for each cluster.

Please insert Table 6 - Main topics and future research developments

In conclusion, given the above-mentioned research findings, there is an evident need to focus on the real benefits derived from XBRL adoption programs, coupled with critical issues that may have hindered full achievement of objectives in terms of financial transparency, comparability, usefulness, and (reduced) burden, especially for SMEs. In the light of the above, a thorough cost-benefit analysis may support the governmental authorities; mandates of XBRL instead of voluntary adoption. This kind of analysis should consider various elements, such as the application context of XBRL (listed and / or unlisted companies), different XBRL extensions (the notes to the financial statements are tagged in XBRL and, in this case, at what level of detail), and the legal characteristics of the jurisdiction (common law or civil law). A crucial opportunity to investigate these issues could be the ESEF adoption by the EU. Furthermore, regulators' decisions should be facilitated by an appropriate communication campaign to raise awareness of the benefits from the adoption of XBRL among financial reporting preparers, markets analysts, and involved companies. 


\section{References}

Ahmadpour, A. (2011), "The improvement of governance decision making using XBRL”, International Journal of E-Business Research, Vol. 7 No 2, pp. 11-18.

Alles, M.G. and Gray, G.L. (2012), "A relative cost framework of demand for external assurance of XBRL filings”, Journal of Information Systems, Vol. 26 No. 1, pp. 103-126.

Amin. K., Eshleman, J.D. and Qian Feng, C. (2018), "The effect of the SEC's XBRL mandate on audit report lags", Accounting Horizons, Vol. 32 No. 1, pp. 1-27.

Apostolou, A.K. and Nanopoulos, K.A. (2009), "Interactive financial reporting using XBRL: An overview of the global markets and Europe", International Journal of Disclosure and Governance, Vol. 6 No. 3, pp. 262-272.

Arnold, V. Bedard, J.C., Phillips, J.R. and Sutton, S.G. (2012), "The impact of tagging qualitative financial information on investor decision making: Implications for XBRL", International Journal of Accounting Information Systems, Vol. 13, pp. 2-20.

Baldwin, A.A. and Trinkle, B.S. (2011), "The Impact of XBRL: A Delphi Investigation", The International Journal of Digital Accounting Research, Vol. 11, pp. 1-24.

Barclay, S., Momen, N., Case-Upton, S., Kuhn, I. and Smith, E. (2011), "End-of-life care conversations with heart failure patients: a systematic literature review and narrative synthesis", British Journal of General Practice, Vol. 61 No. 582, e49-e62.

Bartley, J.W, Chen, A.Y.S. and Taylor, E.Z. (2011), "A Comparison of XBRL Filings to Corporate 10Ks - Evidence from the Voluntary Filing Program”, Accounting Horizons, Vol. 25 No. 2, pp. 227 245.

Bartolacci, F., Caputo, A. and Soverchia, M. (2020) "Sustainability and financial performance of small and medium sized enterprises: A bibliometric and systematic literature review", Business Strategy and the Environment, Vol. 29 No. 3, pp. 1297-1309.

Basoglu, K.A. and White C.E.S.Jr. (2015), "Inline XBRL versus XBRL for SEC reporting”, Journal of Emerging Technologies in Accounting, Vol. 12 No. 1, pp. 189-199.

Bhattacharya, N., Cho, Y.J. and Kim, J.B. (2018) "Leveling the Playing Field between Large and Small Institutions: Evidence from the SEC's XBRL Mandate", The Accounting Review, Vol. 93 No. 5, pp. 51-71.

Birt, J.L., Muthusamy, K. and Bir, P. (2017), "XBRL and the qualitative characteristics of useful financial information", Accounting Research Journal, Vol. 30 No. 1, pp. 107-126.

Blankespoor, E. (2019), "The Impact of Information Processing Costs on Firm Disclosure Choice: Evidence from the XBRL Mandate", Journal of Accounting Research, Vol. 57 No 4, pp. 919-967.

Blankespoor, E., Miller, B.P. and White, H.D. (2014), "Initial evidence on the market impact on the XBRL mandate", Review of Accounting Studies, Vol. 19 No 4, pp. 1468-1503.

Bonsón, E., Cortijo, V. and Escobar, T. (2009), "Towards the global adoption of XBRL using International Financial Reporting Standards (IFRS)", International Journal of Accounting Information Systems, Vol. 10 No. 1, pp. 46-60.

Bonsón, E., Escobar-Rodriguez, T. and Muñoz, F.F. (2007), "The role of metadata language implementation in the European banking supervision network", International Journal of 
Networking and Virtual Organizations, Vol. 4 No. 3, pp. 245-256.

Boritz, J.E., No, W.G., (2009), "Assurance on XBRL-related documents: the case of united technologies corporation", Journal of Information Systems, Vol. 23 No. 2, pp. 49-78.

Boritz, J.E. and No, W.G. (2016), "Computer-assisted functions for auditing XBRL-related documents", Journal of Emerging Technologies in Accounting, Vol. 13 No. 1, pp. 53-83.

Boritz, J.E. and Timoshenko, L.M. (2015), "Firm-specific characteristics of the participants in the SEC's XBRL voluntary filing program”, Journal of Information Systems, Vol. 29 No. 1, pp. 9-36.

Buys, P.W. (2008), "The impact of XBRL on the financial reporting supply chain: a South African case study”, Meditari Accounting Research, Vol. 16 No. 1, pp. 43-58.

Callaghan, J. and Nehmer, R. (2009), "Financial and governance characteristics of voluntary XBRL adopters in the United States", International Journal of Disclosure and Governance, Vol. 6 No. 4, pp. 321-335.

Caputo, A., Marzi, G., Pellegrini, M.M. and Rialti, R. (2018), "Conflict management in family businesses: A bibliometric analysis and systematic literature review", International Journal of Conflict Management, Vol. 29 No. 4, pp. 519-542.

Chen, S., Harris, L., Li, W. and Wu D. (2015), "How Does XBRL Affect the Cost of Equity Capital? Evidence from an Emerging Market", Journal of International Accounting Research, Vol. 14 No. 2, pp. 123-145.

Chen, G., Wang, X. and Zhou, J. (2018), "What Do the Markets Say? Shareholder Wealth Effects of the XBRL Mandate", Journal of Information Systems, Vol. 32 No. 3, pp. 1-21.

Chowdhuri, R., Yoon, V.Y., Redmond, R.T. and Etudo U.O. (2014), "Ontologybased Integration of XBRL Filings for Financial DecisionMaking”, Decision Support Systems, Vol. 68, pp. 64-76.

Cohen, E.E. (2004), “Compromise or Customize: XBRL's Paradoxical Power", Accounting Perspectives, Vol. 32 No. 2, pp. 187-206.

Cormier, D., Dufour, D., Luu, P., Teller, P. and Teller, R. (2019), “The Relevance of XBRL Voluntary Disclosure for Stock Market Valuation: The Role of Corporate Governance", Canadian Journal of Administrative Sciences, Vol. 36 No. 1, pp. 113-127.

Dabić, M., Maley, J., Dana, L.-P., Novak, I., Pellegrini, M.M. and Caputo, A. (2019), "Pathways of SME internationalization: a bibliometric and systematic review", Small Business Economics, https://doi.org/10.1007/s11187-019-00181-6.

Debreceny, R., Farewell, S., Piechocki, M., Felden, C. and Graning, A., (2010) "Does it add up? Early evidence on the data quality of XBRL filings to the SEC", Journal of Accounting and Public Policy, Vol. 29 No. 3, pp. 296-306.

Debreceny, R.S., Farewell, S.M., Piechocki, M., Felden, C., Gräning, A. and d'Eri, A. (2011), "Flex or Break? Extensions in XBRL Disclosures to the SEC", Accounting Horizons, Vol. 25 No. 4, pp. 631-657.

Debreceny, R., Felden, C., Ochocki, B., Piechocki, M., and Piechocki, M. (2009), XBRL for Interactive Data. Engineering the Information Value Chain, Springer, Heidelberg.

Dhole, S. Lobo, G.J. Mishra, S. and Pal, A.M., (2015), "Effects of the SEC's XBRL mandate on financial reporting comparability", International Journal of Accounting Information Systems, Vol 
19, pp. 29-44.

Doolin, B. and Troshani, I. (2004), "XBRL: a research note", Qualitative Research in Accounting \& Management, Vol. 1 No. 2, pp. 93-104.

Du, H., Vasarhelyi, M.A. and Zheng, X. (2013) "XBRL Mandate: Thousands of Filing Errors and So What?", Journal of Information Systems, Vol. 27 No. 1, pp. 61-78.

Du, H. and Wu, K. (2018), "XBRL Mandate and Timeliness of Financial Reporting: Do XBRL Filings Take Longer?", Journal of Emerging Technologies in Accounting, Vol. 15 No. 1, pp. 57-75.

Efendi, J., Park, J.D. and Subramaniam, C. (2016), "Does the XBRL Reporting Format Provide Incremental Information Value? A Study Using XBRL Disclosures During the Voluntary Filing Program", Abacus, Vol. 52 No 2, pp. 259-285.

Escobar-Rodríguez, T., and Gago-Rodríguez, S. (2012), ""We were the first to support a major is innovation". Research into the motivations of Spanish pioneers in XBRL", Revista de Contabilidad, Vol. 15 No. 1, pp. 91-108.

Etudo, U., Yoon, V. and Liu, D. (2017), "Financial Concept Element Mapper (FinCEM) for XBRL interop-erability: Utilizing the M3 Plus method", Decision Support Systems, Vol. 98, pp. 36-48.

Farewell, S.M, Hao, L., Kashyap, V. and Pinsker R.E. (2017), “A Field Study Examining the Indian Ministry of Corporate Affairs' XBRL Implementation”, Journal of Information Systems, Vol. 31 No. 1, pp. 103-117.

Felden, C. (2011), "Characteristics of XBRL adoption in Germany", Journal of Management Control, Vol. 22 No. 2, pp. 161-186.

Felo, A.J., Kim, J.W. and Lim, J. (2018), “Can XBRL Detailed Tagging of Footnotes Improve Financial Analysts' Information Environment?”, International Journal of Accounting Information Systems, Vol. 28, pp. 45-58.

Ferreira, F.A.F. (2018), "Mapping the field of arts-based management: Bibliographic coupling and cocitation analyses", Journal of Business Research, Vol. 85, 348-357.

Fradeani, A., Panizzolo, D. and Metushi, E. (2016), "Financial Reporting in XBRL: First Evidence on Financial Statement Notes of Italian Unlisted Companies", The International Journal of Digital Accounting Research, Vol. 16, pp. 85-115.

Geiger, M.A., North, D.S. and Selby, D.D. (2014), "Releasing information in XBRL: Does it improve information asymmetry for early U. S. Adopters?", Academy of Accounting and Financial Studies Journal, Vol. 18 No 4, pp. 66-83.

Gonzalbez, J.M. and Rodriguez, M.M. (2012), "XBRL and integrated reporting: The Spanish accounting association taxonomy approach", International Journal of Digital Accounting Research, Vol. 12, pp. 59-91.

Gray, G.L. and Miller, D.W. (2009), "XBRL: Solving real-world problems”, International Journal of Disclosure and Governance, Vol. 6 No. 3, pp. 207-223.

Hao, L.H., Zhang, J. and Fang, J. (2014), "Does voluntary adoption of XBRL reduce cost of equity capital?", International Journal of Accounting \& Information Management, Vol. 22 No. 2, pp. 86102.

Hodge, F.D., Kennedy, J.J. and Maines, L.A., (2004), "Does search-facilitating technology improve the 
transparency of financial reporting?", The Accounting Review, Vol. 79 No. 3, pp. 687-703.

Jackson, L.A. and Kwansa, F., (2011), "Digitizing financial reporting: A profile of early hospitality industry XBRL adopters and implications for the industry", Journal of Hospitality Financial Management, Vol. 19 No. 1, pp. 27-50.

Janvrin, D.J., Pinsker, R.E. and Mascha, M.F. (2013), "XBRL-Enabled, Spreadsheet, or PDF? Factors Influencing Exclusive User Choice of Reporting Technology", Journal of Information Systems, Vol. 27 No. 2, pp. 35-49.

Kaya, D. (2014), "The influence of firm-specific characteristics on the extent of voluntary disclosure in XBRL: Empirical analysis of SEC filings", International Journal of Accounting and Information Management, Vol. 22 No. 1, pp. 2-17.

Kaya, D. and Pronobis, P. (2016), "The benefits of structured data across the information supply chain: Initial evidence on XBRL adoption and loan contracting of private firms", Journal of Accounting and Public Policy, Vol. 35 No. 4, pp. 417-436.

Kernan, K. (2009), XBRL. The Story of Our New Language, American Institute of Certified Public Accountants, New York, NY.

Kim, J., Lim, J.-H. and No, W.G. (2012), "The Effect of First Wave Mandatory XBRL Reporting across the Financial Information Environment”, Journal of Information Systems, Vol. 26 No. 1, pp. 127153.

Knebel, S. and Seele, P. (2015), "Quo vadis GRI? A (critical) assessment of GRI 3.1 A+ non-financial reports and implications for credibility and standardization", Corporate Communications, Vol. 20 No. 2, pp. 196-212.

La Torre, M., Valentinetti, D., Dumay, J. and Rea, M.A. (2018), "Improving corporate disclosure through XBRL: An evidence-based taxonomy structure for integrated reporting", Journal of Intellectual Capital, Vol. 19 No. 2, pp. 338-366.

Lai, S.C., Lin, Y.S., Lin, Y.H. and Huang, H.W. (2015), "XBRL adoption and cost of debt", International Journal of Accounting and Information Management, Vol. 23 No. 2, pp. 199-216.

Lambert, S.L., Krieger, K. and Mauck, N. (2019), “Analysts' forecasts timeliness and accuracy postXBRL", International Journal of Accounting \& Information Management, Vol. 27 No. 1, pp. 158.

Li, S. and Nwaeze, E.T. (2015), "The association between extensions in XBRL disclosures and financial information environment", Journal of Information Systems, Vol. 29 No. 3, pp. 73-99.

Liu, C. (2013), “XBRL: A new global paradigm for business financial reporting”, Journal of Global Information Management, Vol. 21 No. 3, pp. 60-80.

Liu, C., Luo, X., Sia, C.L., O'Farrell, G. and Teo, H.H. (2014), "The impact of XBRL adoption in PR China", Decision Support Systems, Vol. 59 No. 1, pp. 242-249.

Liu, C., Luo, X.R. and Wang, F.L. (2017), "An empirical investigation on the impact of XBRL adoption on information asymmetry: Evidence from Europe", Decision Support Systems, Vol. 93, pp. 4250 .

Liu, C., Wang, T. and Yao, L.J. (2014), “XBRL's Impact on Analyst Forecast Behavior: An Empirical Study", Journal of Accounting and Public Policy, Vol. 33 No. 1, pp. 69-82. 
Locke, J. and Lowe, A. (2007), "XBRL: An (Open) Source of Enlightenment or Disillusion?", European Accounting Review, Vol. 16 No. 3, pp. 585-623.

Locke, J., Lowe, A. and Lymer, A. (2015), "Interactive Data and Retail Investor Decision-Making: An Experimental Study", Accounting \& Finance, Vol. 55 No. 1, pp. 213-240.

López-Fernández, M.C., Serrano-Bedia, A.M. and Pérez-Pérez, M. (2016), "Entrepreneurship and Family Firm Research: A Bibliometric Analysis of An Emerging Field", Journal of Small Business Management, Vol. 54 No. 2, pp. 622-639.

Ly, K. (2012) "Extensible business reporting language for financial reporting (XBRL fr) and financial analysts' activity: Early evidence", Academy of Accounting and Financial Studies Journal, Vol. 16 No. 2, pp. 25-44.

Marzi, G., Dabić, M., Daim, T. and Garces, E. (2017), "Product and process innovation in manufacturing firms: a 30-year bibliometric analysis", Scientometrics, Vol. 113 No. 2, pp. 673704.

Muñoz, F.F., Valentinetti, D., Rodríguez, M.M. and Nieto, A.M. (2018), "The role of XBRL on EMAS reporting: An analysis of organisational values compatibility", Scientific Annals of Economics and Business, Vol. 65 No. 4, pp. 497-514.

Nel, G.F. and Steenkamp, L.P. (2008), "An exploratory study of chartered accountants' awareness and understanding of XBRL”, Meditari Accountancy Research, Vol. 16 No. 1, pp. 79-93.

Panizzolo, D. Fradeani, A. and Metushi, E. (2017), "Financial reporting practices of Italian SMEs: Why do they disclose more?", International Journal of Digital Accounting Research, Vol. 17, pp. 111137.

Perdana, A., Robb, A. and Rohde, F. (2015), "An integrative review and synthesis of XBRL research in academic journals", Journal of Information Systems, Vol. 29 No. 1, 115-153.

Piechocki, M., Felden, C., Gräning, A. and Debreceny, R. (2009), "Design and standardisation of XBRL solutions for governance and transparency", International Journal of Disclosure and Governance, Vol. 6 No. 3, 224-240.

Pinsker, R. (2003), “XBRL awareness in auditing: A sleeping giant?”, Managerial Auditing Journal, Vol. 18 No. 9, pp. 732-736.

Pinsker, R.E. and Felden, C. (2016), "Professional role and normative pressure: The case of voluntary XBRL adoption in Germany", Journal of Emerging Technologies in Accounting, Vol. 13 No. 1, pp. 95-118.

Pittaway, L. and Cope, J. (2007), "Entrepreneurship education a systematic review of the evidence", International Small Business Journal, Vol. 25 No. 5, pp. 479-510.

Plumlee, R.D. and Plumlee, M.A. (2008), “Assurance on XBRL for financial reporting”, Accounting Horizons, Vol. 22 No. 3, pp. 353-368.

Premuroso, R.F. and Bhattacharya, S. (2008), "Do early and voluntary filers of financial information in XBRL format signal superior corporate governance and operating performance?", International Journal of Accounting Information Systems, Vol. 9 No. 1, pp. 1-20.

Ragothaman (2012), "Voluntary XBRL adopters and firm characteristics: An empirical analysis", The International Journal of Digital Accounting Research, Vol. 12, pp. 93-119. 
Richards, J. and Tower, G. (2004), "Progress on XBRL from an Australian perspective", Australian Accounting Review, Vol. 14 No. 32, pp. 81-88.

Roohani, S., Furusho, Y. and Koizumi, M. (2009), "XBRL: Improving transparency and monitoring functions of corporate governance", International Journal of Disclosure and Governance, Vol. 6 No. 4, pp. 355-369.

Roohani, S., Xianming, Z., Capozzoli, E. and Lamberton B. (2010), "Analysis of XBRL Literature: A Decade of Progress and Puzzle", The International Journal of Digital Accounting Research, Vol. 10, pp. 131-147.

Sassetti, S., Marzi, G., Cavaliere, V. and Ciappei, C. (2018), "Entrepreneurial cognition and socially situated approach: a systematic and bibliometric analysis", Scientometrics, Vol. 116 No. 3, pp. $1675-1718$.

Satoh, F. (2011), "XBRL taxonomy for estimating the effects of greenhouse gas emissions on corporate financial positions", International Journal of E-Business Research, Vol. 7 No. 2, pp. 34-55.

Scherr, E. and Ditter, D. (2017), "Customization versus Standardization in Electronic Financial Reporting: Early Evidence from the SEC XBRL Mandate", Journal of Information Systems, Vol. 31 No. 2, pp. 125-148.

Seele, P. (2016), "Digitally unified reporting: how XBRL-based real-time transparency helps in combining integrated sustainability reporting and performance control", Journal of Cleaner Production, Vol. 136 Part A, pp. 65-77.

Seele, P. (2017), "Predictive Sustainability Control: A review assessing the potential to transfer big data driven 'predictive policing' to corporate sustainability management", Journal of Cleaner Production, Vol. 153, pp. 673-686.

Shan, Y.G. and Troshani, I. (2016), "The effect of mandatory XBRL and IFRS adoption and audit fees: Evidence from the Shanghai Stock Exchange", International Journal of Managerial Finance, Vol. 12 No. 2, pp. 109-135.

Shan, Y.G., Troshani, I. and Richardson, G. (2015), "An empirical comparison of the effect of XBRL on audit fees in the US and Japan", Journal of Contemporary Accounting and Economics, Vol. 11 No. 2, pp. 89-103.

Sohl, S.N. Waymire, T.R. and Webb, T.Z. (2018), "Determinants of Bifurcated Local Government Reporting Lag: The Potential for XBRL to Improve Timeliness", Journal of Emerging Technologies in Accounting, Vol. 15 No. 1, pp. 121-140.

Srivastava, R.P. and Kogan, A. (2010), "Assurance on XBRL instance document: A conceptual framework of assertions", International Journal of Accounting Information Systems, Vol. 11 No. 3, pp. 261-273.

Thorpe, R., Holt, R., Macpherson, A. and Pittaway, L., (2005), "Using knowledge within small and medium-sized firms: A systematic review of the evidence", International Journal of Management Reviews, Vol. 7 No. 4, pp. 257-281.

Tranfield, D., Denyer, D. and Smart, P. (2003), "Towards a methodology for developing evidenceinformed management knowledge by means of systematic review", British Journal of Management, Vol. 14 No. 3, pp. 207-222.

Troshani, I., Janssen, M., Lymer A. and Parker, L.D. (2018), "Digital transformation of business-to- 
government reporting: An institutional work perspective", International Journal of Accounting Information Systems, Vol. 31, pp. 17-36.

Valentinetti, D. and Rea, M.A. (2012), "IFRS Taxonomy and financial reporting practices: The case of Italian listed companies", International Journal of Accounting Information System, Vol. 3 No. 2, pp. $163-180$.

Valentinetti, D. and Rea, M.A. (2013), "XBRL for Financial Reporting: Evidence on Italian GAAP versus IFRS", Accounting Perspectives, Vol. 12 No. 3, pp. 237-259.

van Eck, N.J. and Waltman, L. (2007), "VOS: a new method for visualizing similarities between objects", in: Decker, R. and Lenz, H.J. (Eds.), Advances in Data Analysis. Studies in Classification, Data Analysis, and Knowledge Organization, Springer, Berlin, Heidelberg, pp. 299-306.

van Eck, N.J. and Waltman, L. (2010), "Software survey: VOSviewer, a computer program for bibliometric mapping”, Scientometrics, Vol. 84 No. 2, pp. 523-538.

Vasarhelyi, M.A., Chan, D.Y. and Krahel, J.P. (2012), "Consequences of XBRL Standardization on Financial Statement Data", Journal of Information Systems, Vol. 26 No. 1, pp. 155-167.

Yen, J.-C. and Wang, T. (2015), "The Association between XBRL Adoption and Market Reactions to Earnings Surprises”, Journal of Information Systems, Vol. 29 No. 3, pp. 51-71.

Yoon, H. Zo, H. and Ciganek, A.P. (2011) “Does XBRL adoption reduce information asymmetry?", Journal of Business Research, Vol. 64 No 2, pp. 157-163.

Zhang, Y., Guan, Y. and Kim, J. (2019), "XBRL adoption and expected crash risk", Journal of Accounting and Public Policy, Vol. 38 No. 1, pp. 31-52.

Zhou, J. (2019), "Does one size fit all? Evidence on XBRL adoption and 10-K filing lag", Accounting and Finance, https://doi.org/10.1111/acfi.12444.

Zhu, H. and Wu, H. (2011), "Interoperability of XBRL financial statements in the U.S”, International Journal of e-Business Research, Vo.7 No. 2, pp. 18-33.

Zupic, I. and Čater, T. (2015), "Bibliometric methods in management and organization", Organizational Research Methods, Vol. 18 No., 3, pp. 429-472. 
Tables in order of appearance in the manuscript

Table 7 - Journals with at least 10 citations

\begin{tabular}{|c|c|c|c|c|}
\hline Rank & Journal & Publications & Citations & $\begin{array}{l}\text { Citations per } \\
\text { publication }\end{array}$ \\
\hline 1 & Journal of Information Systems & 17 & 310 & 18.24 \\
\hline 2 & $\begin{array}{l}\text { International Journal of Accounting Information } \\
\text { Systems }\end{array}$ & 12 & 433 & 36.08 \\
\hline 3 & $\begin{array}{l}\text { International Journal of Digital Accounting } \\
\text { Research }\end{array}$ & 9 & 112 & 12.44 \\
\hline 4 & Journal of Emerging Technologies in Accounting & 8 & 24 & 3.00 \\
\hline 5 & $\begin{array}{l}\text { International Journal of Accounting and } \\
\text { Information Management }\end{array}$ & 7 & 55 & 7.86 \\
\hline 6 & $\begin{array}{l}\text { International Journal of Disclosure and } \\
\text { Governance }\end{array}$ & 5 & 107 & 21.40 \\
\hline 7 & Decision Support Systems & 5 & 60 & 12.00 \\
\hline 8 & International Journal of e-Business Research & 5 & 24 & 4.80 \\
\hline 9 & Journal of Accounting and Public Policy & 4 & 143 & 35.75 \\
\hline 10 & Accounting Horizons & 4 & 81 & 20.25 \\
\hline 11 & Accounting Review & 3 & 230 & 76.67 \\
\hline 12 & Journal of Business Research & 3 & 117 & 39.00 \\
\hline 13 & Accounting Perspectives & 3 & 20 & 6.67 \\
\hline 14 & Accounting and Finance & 3 & 13 & 4.33 \\
\hline 15 & Managerial Auditing Journal & 2 & 85 & 42.50 \\
\hline 16 & Electronic Markets & 2 & 42 & 21.00 \\
\hline 17 & Journal of Cleaner Production & 2 & 21 & 10.50 \\
\hline 18 & $\begin{array}{l}\text { International Journal of Managerial and Financial } \\
\text { Accounting }\end{array}$ & 2 & 14 & 7.00 \\
\hline 19 & $\begin{array}{l}\text { Academy of Accounting and Financial Studies } \\
\text { Journal }\end{array}$ & 2 & 10 & 5.00 \\
\hline 20 & European Journal of Innovation Management & 1 & 60 & 60.00 \\
\hline 21 & Review of Accounting Studies & 1 & 44 & 44.00 \\
\hline 22 & European Accounting Review & 1 & 38 & 38.00 \\
\hline 23 & $\begin{array}{l}\text { Qualitative Research in Accounting \& } \\
\text { Management }\end{array}$ & 1 & 28 & 28.00 \\
\hline 24 & Canadian Accounting Perspectives & 1 & 24 & 24.00 \\
\hline 25 & British Accounting Review & 1 & 23 & 23.00 \\
\hline 26 & Pacific Accounting Review & 1 & 20 & 20.00 \\
\hline 27 & Journal of Global Information Management & 1 & 19 & 19.00 \\
\hline 28 & Behavioral Research in Accounting & 1 & 17 & 17.00 \\
\hline 29 & Journal of Financial Regulation and Compliance & 1 & 15 & 15.00 \\
\hline 30 & Corporate Communications & 1 & 14 & 14.00 \\
\hline 31 & Australian Accounting Review & 1 & 11 & 11.00 \\
\hline 32 & Information and Management & 1 & 11 & 11.00 \\
\hline 33 & Journal of Management Control & 1 & 10 & 10.00 \\
\hline
\end{tabular}


Table 8 - Publications by rank

\begin{tabular}{ccccc}
\hline ABDC Rank & Publications & $\mathbf{\%}$ & Citations & $\begin{array}{c}\text { Citations per } \\
\text { publication }\end{array}$ \\
\hline A* & 13 & $9.15 \%$ & 383 & 29.46 \\
A & 54 & $38.03 \%$ & 1230 & 22.78 \\
B & 19 & $13.38 \%$ & 236 & 12.42 \\
C & 36 & $25.35 \%$ & 371 & 10.31 \\
D & 0 & $0.00 \%$ & 0 & 0.00 \\
Not ranked & 20 & $14.08 \%$ & 98 & 4.90 \\
\hline
\end{tabular}

Table 9 - Countries by publication

\begin{tabular}{|c|c|c|c|c|c|}
\hline Rank & Country & Publications & $\%$ & Citations & $\begin{array}{c}\text { Citation } \\
\text { per } \\
\text { Publication } \\
\end{array}$ \\
\hline 1 & United States & 71 & $50.00 \%$ & 1376 & 19.38 \\
\hline 2 & Australia & 13 & $9.15 \%$ & 157 & 12.08 \\
\hline 3 & Canada & 10 & $7.04 \%$ & 166 & 16.60 \\
\hline 4 & China & 6 & $4.23 \%$ & 29 & 4.83 \\
\hline 5 & Italy & 6 & $4.23 \%$ & 48 & 8.00 \\
\hline 6 & Spain & 6 & $4.23 \%$ & 85 & 14.17 \\
\hline 7 & Germany & 5 & $3.52 \%$ & 40 & 8.00 \\
\hline 8 & New Zealand & 3 & $2.11 \%$ & 86 & 28.67 \\
\hline 9 & Switzerland & 3 & $2.11 \%$ & 35 & 11.67 \\
\hline 10 & United Kingdom & 3 & $2.11 \%$ & 22 & 7.33 \\
\hline 11 & Iran & 2 & $1.41 \%$ & 6 & 3.00 \\
\hline 12 & Japan & 2 & $1.41 \%$ & 8 & 4.00 \\
\hline 13 & Taiwan & 2 & $1.41 \%$ & 15 & 7.50 \\
\hline 14 & Cyprus & 1 & $0.70 \%$ & 1 & 1.00 \\
\hline 15 & Greece & 1 & $0.70 \%$ & 13 & 13.00 \\
\hline 16 & Hong Kong & 1 & $0.70 \%$ & & 0.00 \\
\hline 17 & India & 1 & $0.70 \%$ & & 0.00 \\
\hline 18 & Indonesia & 1 & $0.70 \%$ & 1 & 1.00 \\
\hline 19 & Israel & 1 & $0.70 \%$ & & 0.00 \\
\hline 20 & Lithuania & 1 & $0.70 \%$ & 2 & 2.00 \\
\hline 21 & Singapore & 1 & $0.70 \%$ & 143 & 143.00 \\
\hline 22 & South Korea & 1 & $0.70 \%$ & 83 & 83.00 \\
\hline 23 & Uruguay & 1 & $0.70 \%$ & 2 & 2.00 \\
\hline
\end{tabular}


Table 10 - Most cited articles

\begin{tabular}{lll}
\hline \multicolumn{1}{c}{ Rank } & \multicolumn{1}{c}{ Article } & Citations \\
\hline 1 & Hodge F.D., Kennedy J.J., Maines L.A. (2004) & 219 \\
2 & Debreceny R., Gray G.L. (2001) & 143 \\
3 & Debreceny R., Farewell S., Piechocki M., Felden C., Gräning A. (2010) & 95 \\
4 & Yoon H., Zo H., Ciganek A.P. (2011) & 83 \\
5 & Premuroso R.F., Bhattacharya S. (2008) & 77 \\
6 & Kim J.W., Lim J.-H., No W.G. (2012) & 61 \\
7 & Troshani I., Doolin B. (2007) & 60 \\
8 & Bonsón E., Cortijo V., Escobar T. (2009) & 55 \\
9 & Arnold V., Bedard J.C., Phillips J.R., Sutton S.G. (2012) & 47 \\
10 & Efrim Boritz J., No W.G. (2009) & 47 \\
\hline
\end{tabular}

Table 11 - Most prolific authors

\begin{tabular}{|c|c|c|c|c|}
\hline Rank & Author & Publications & Citations & Citations per publication \\
\hline 1 & Liu C. & 7 & 125 & 17.86 \\
\hline 2 & Troshani I. & 5 & 105 & 21.00 \\
\hline 3 & Valentinetti D. & 5 & 41 & 8.20 \\
\hline 4 & Debreceny R. & 4 & 273 & 68.25 \\
\hline 5 & Felden $\mathrm{C}$. & 4 & 136 & 34.00 \\
\hline 6 & No W.G. & 4 & 134 & 33.50 \\
\hline 7 & Rea M.A. & 4 & 41 & 10.25 \\
\hline 8 & Bedard J.C. & 3 & 59 & 19.67 \\
\hline 9 & $\mathrm{Du} \mathrm{H}$. & 3 & 28 & 9.33 \\
\hline 10 & Gray G.L. & 3 & 182 & 60.67 \\
\hline 11 & Hao L. & 3 & 12 & 4.00 \\
\hline 12 & Lymer A. & 3 & 35 & 11.67 \\
\hline 13 & O'farrell G. & 3 & 42 & 14.00 \\
\hline 14 & Piechocki M. & 3 & 155 & 51.67 \\
\hline 15 & Pinsker R.E. & 3 & 23 & 7.67 \\
\hline 16 & Roohani S. & 3 & 49 & 16.33 \\
\hline 17 & Seele P. & 3 & 38 & 12.67 \\
\hline 18 & Trinkle B.S. & 3 & 98 & 32.67 \\
\hline 19 & Vasarhelyi M.A. & 3 & 70 & 23.33 \\
\hline 20 & Wang $\mathrm{T}$. & 3 & 63 & 21.00 \\
\hline 21 & Wu H. & 3 & 55 & 18.33 \\
\hline 22 & Zhu H. & 3 & 55 & 18.33 \\
\hline
\end{tabular}


Table 12 - Main topics and future research developments

\begin{tabular}{|c|c|c|}
\hline Cluster & Main topics & Future research developments \\
\hline 1. Adoption issues & $\begin{array}{l}\text { Operational implementation of } \\
\text { XBRL in different contexts and } \\
\text { countries } \\
\text { - } \quad \text { Features of the early XBRL } \\
\text { adopters } \\
\text { - Motivations pushing towards } \\
\text { XBRL mandatory/voluntary } \\
\text { adoption } \\
\text { The ESEF mandate on EU } \\
\text { regulated markets }\end{array}$ & $\begin{array}{l}\text { - Comparative analysis of XBRL } \\
\text { adoption in different countries to } \\
\text { better understand reasons and } \\
\text { implications associated with } \\
\text { XBRL mandatory or not } \\
\text { adoptions } \\
\text { Investigation of the impact of } \\
\text { XBRL adoption on companies' } \\
\text { financial performance } \\
\text { Analysis of XBRL adoption by } \\
\text { public entities and relative } \\
\text { implications } \\
\text { Factors that may influence the } \\
\text { choice of government authorities } \\
\text { to mandate XBRL instead of } \\
\text { adopting it on a voluntary basis }\end{array}$ \\
\hline 2. financial reporting & $\begin{array}{l}\text { - XBRL characteristics and } \\
\text { potentials for financial reporting } \\
\text { XBRL taxonomies and } \\
\text { extensions } \\
\text { - } \quad \text { Comparability, interoperability, } \\
\text { and timeliness of financial } \\
\text { reporting } \\
\text { - XBRL-capable accounting } \\
\text { software } \\
\text { iXBRL adoption }\end{array}$ & $\begin{array}{l}\text { - Impacts of XBRL } \\
\text { implementation outside the US } \\
\text { and the SEC context } \\
\text { Effects of XBRL on SMEs' } \\
\text { financial reporting } \\
\text { XBRL implementation with } \\
\text { accounting standards different } \\
\text { from IFRS } \\
\text { The effects on preparing the } \\
\text { financial statements of the } \\
\text { features and limits of XBRL- } \\
\text { capable accounting software } \\
\text { The influence by taxonomies in } \\
\text { terms of content and extent of } \\
\text { disclosure (especially with } \\
\text { reference to SMEs) } \\
\text { The impact of iXBRL adoption } \\
\text { on financial reporting }\end{array}$ \\
\hline $\begin{array}{l}\text { 3. decision making, market efficiency, } \\
\text { corporate governance }\end{array}$ & $\begin{array}{ll}\text { - } & \text { Transparency and forecast } \\
& \text { accuracy } \\
\text { - } & \text { Information asymmetry } \\
\text { - } & \text { Corporate governance impacts }\end{array}$ & $\begin{array}{l}\text { The supports for SMEs in the } \\
\text { XBRL implementation with } \\
\text { which getting its benefits } \\
\text { The role that XBRL can play in } \\
\text { leading better decision-making } \\
\text { processes }\end{array}$ \\
\hline 4. audit and assurance & $\begin{array}{ll}\text { - } & \text { XBRL assurance } \\
\text { - } & \text { The impacts of XBRL adoption } \\
\text { on audit fees } \\
\text { - } \quad \text { iXBRL adoption }\end{array}$ & $\begin{array}{l}\text { - The impact of iXBRL adoption } \\
\text { on audit and assurance issues }\end{array}$ \\
\hline 5. non-financial reporting & $\begin{array}{l}\text { XBRL and Integrating Reporting } \\
\text { - XBRL as a tool to improve } \\
\text { transparency of non-financial } \\
\text { reporting } \\
\text { XBRL within the corporate } \\
\text { planning and control system }\end{array}$ & $\begin{array}{l}\text { - The role of XBRL in the } \\
\text { different fields of non-financial } \\
\text { reporting (environmental, social, } \\
\text { carbon, etc.) } \\
\text { How XBRL could improve } \\
\text { standardization and } \\
\text { comparability of sustainability } \\
\text { reporting practices across } \\
\text { national borders }\end{array}$ \\
\hline
\end{tabular}




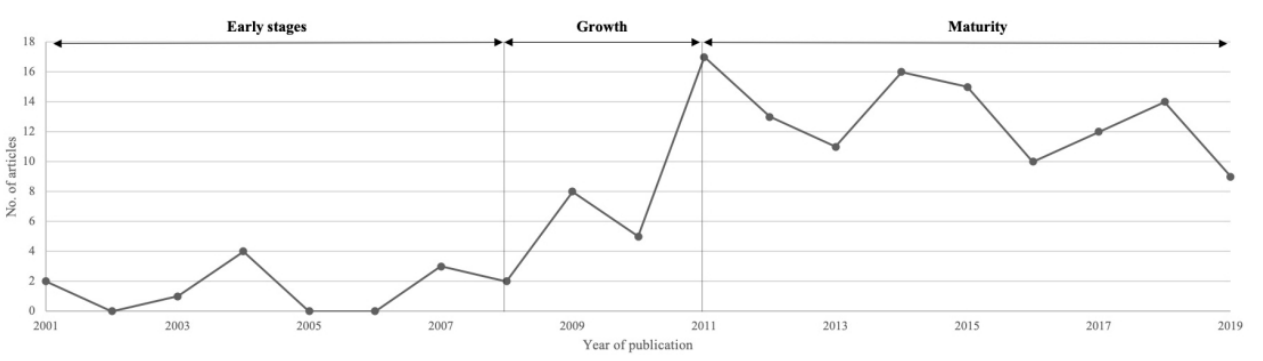

Publication by year

$329 \times 101 \mathrm{~mm}(144 \times 144$ DPI $)$ 
Network diagram of the largest connected set of cited references

$293 \times 186 \mathrm{~mm}(144 \times 144 \mathrm{DPI})$ 


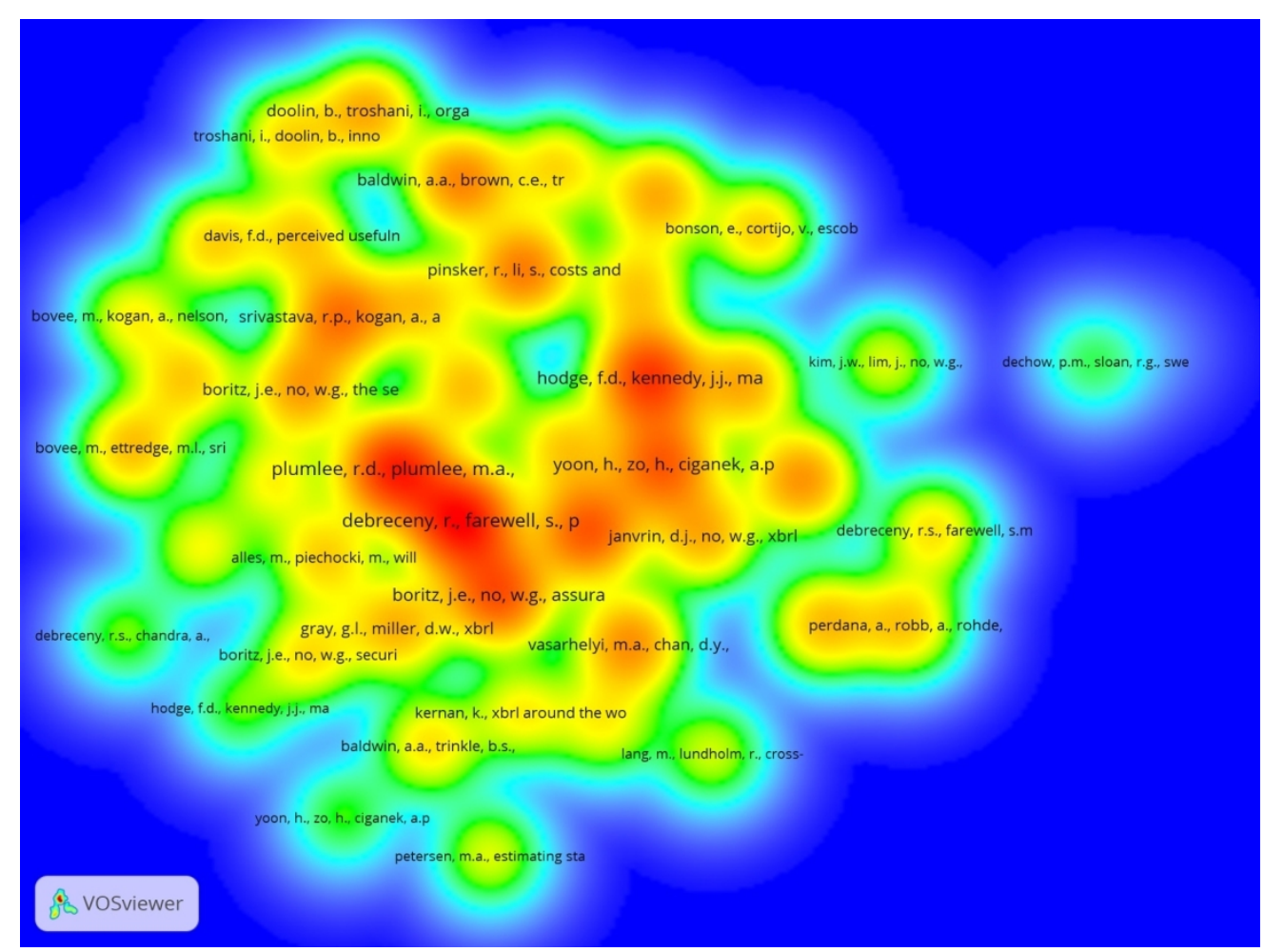

Density diagram of the largest connected set of cited references $298 \times 223 \mathrm{~mm}(144 \times 144$ DPI) 


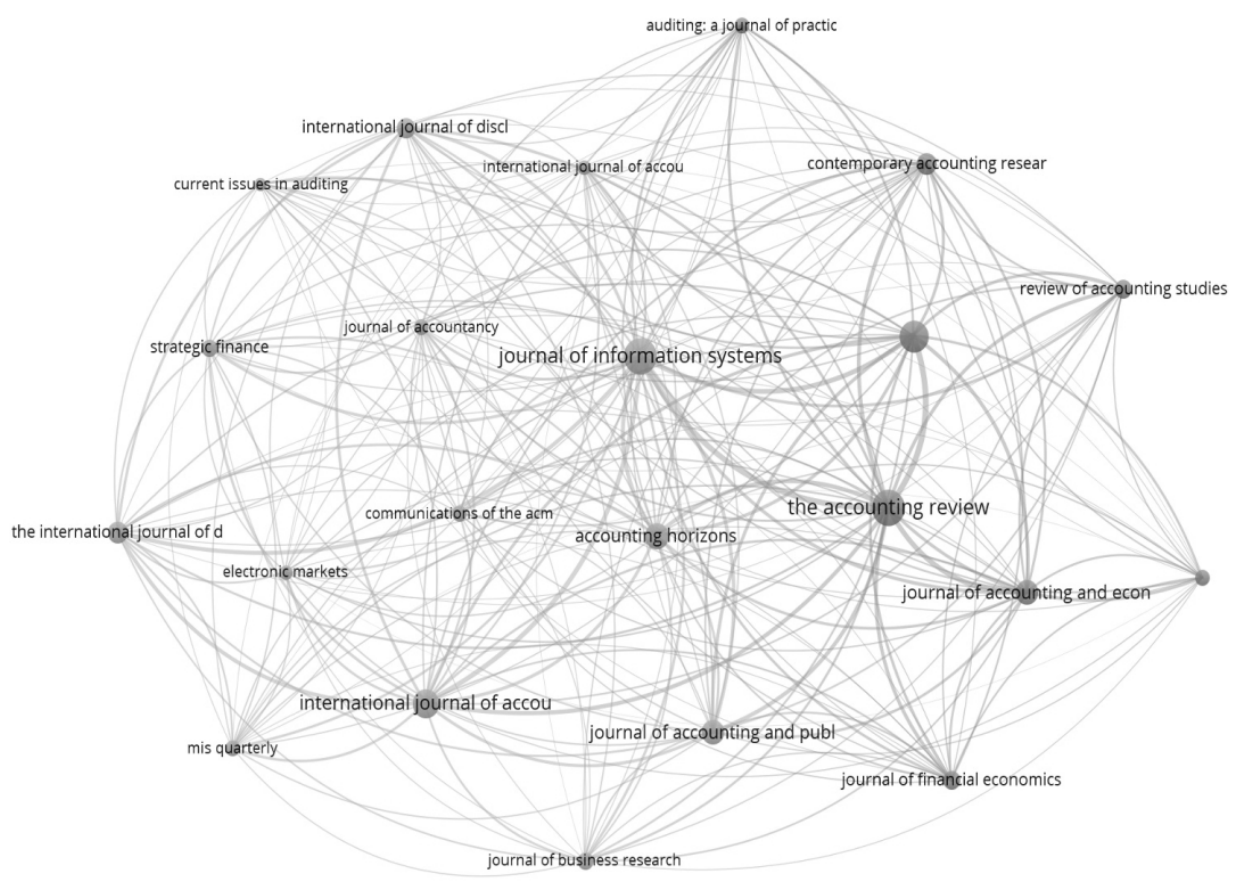

Network diagram of the largest connected set of cited sources

$280 \times 191 \mathrm{~mm}(144 \times 144$ DPI $)$ 


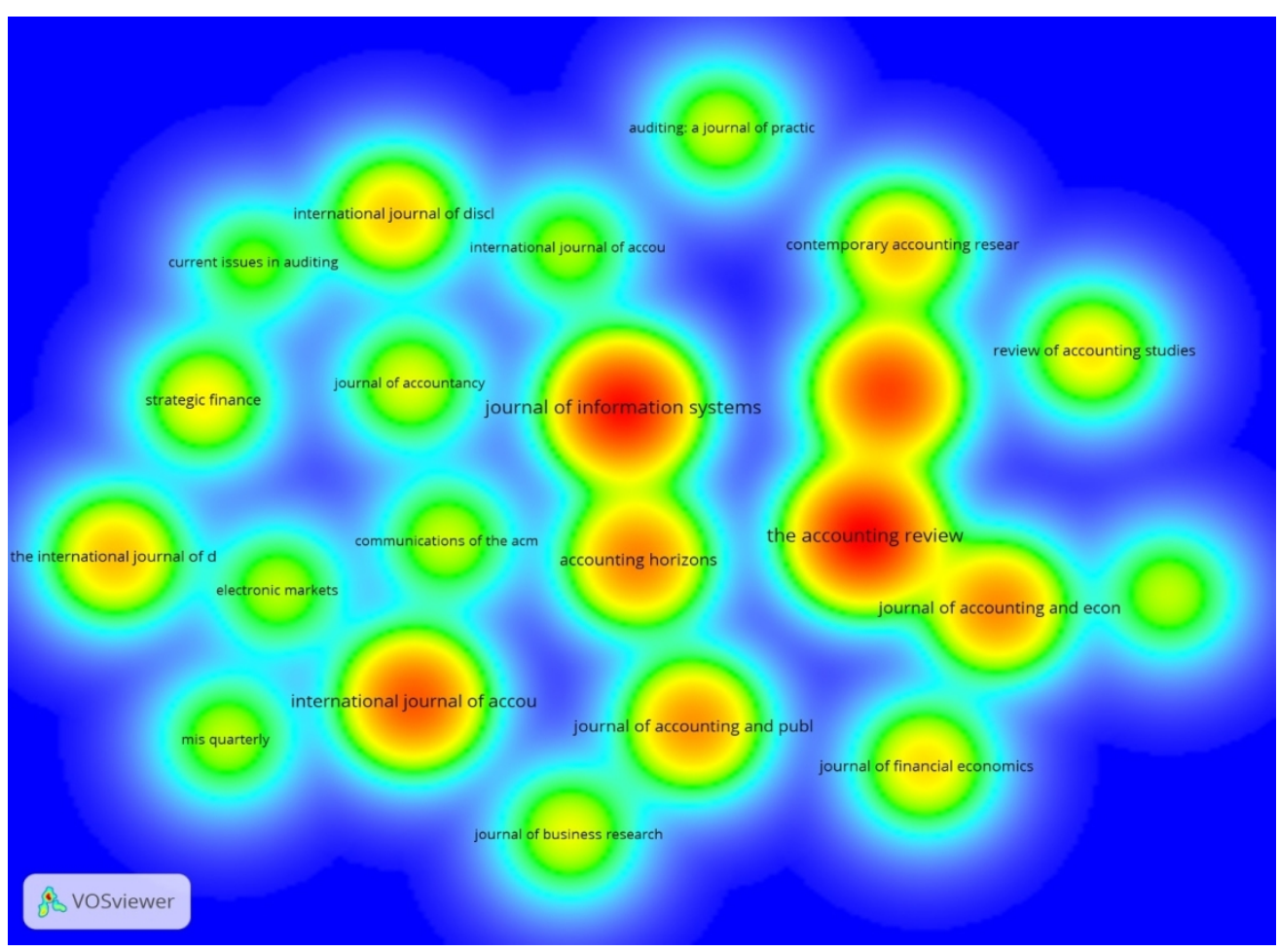

Density diagram of the largest connected set of cited sources $269 \times 197 \mathrm{~mm}(144 \times 144 \mathrm{DPI})$ 
Density diagram of the largest connected set of cited authors $258 \times 198 m m(144 \times 144$ DPI $)$ 


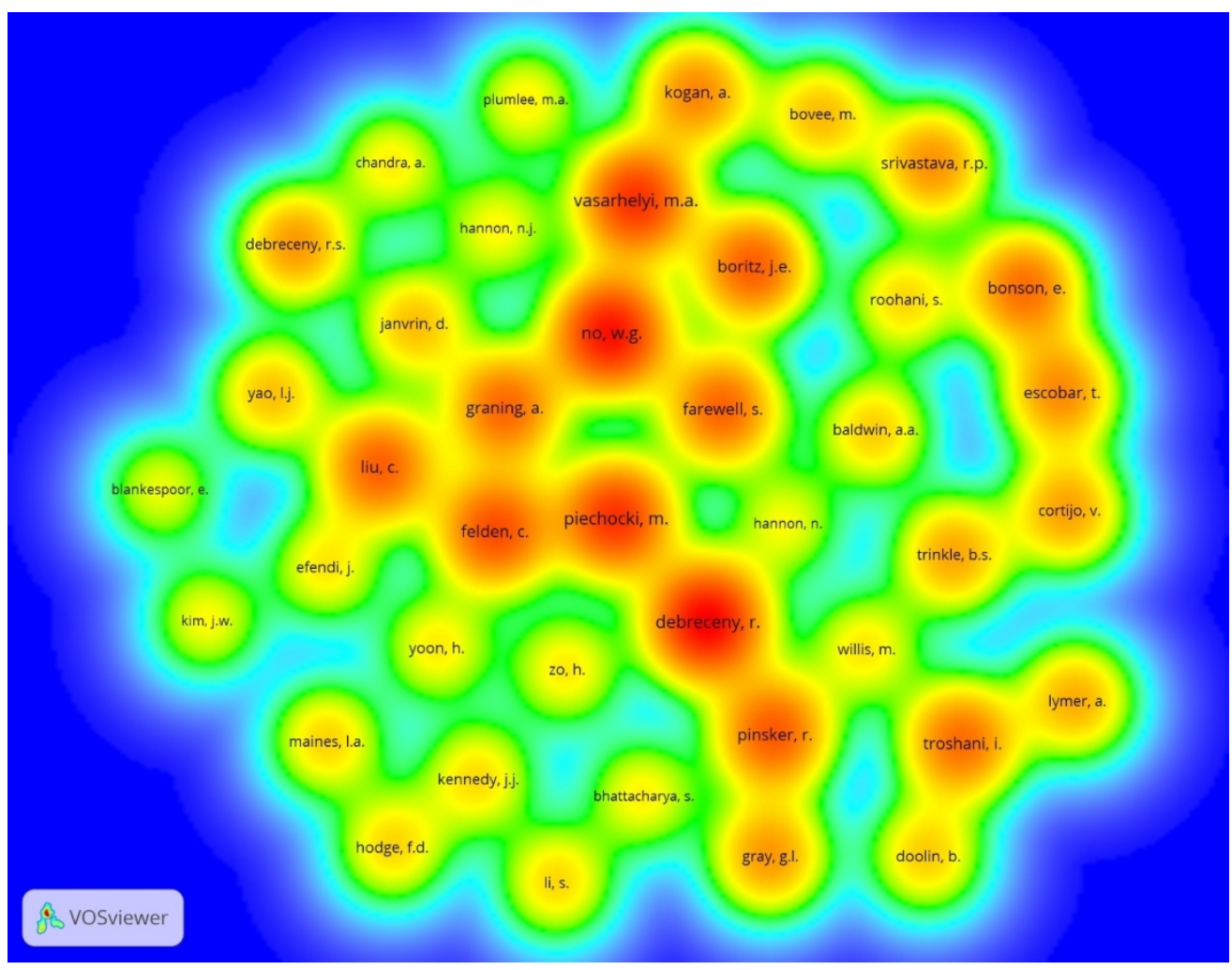

Network diagram of the largest connected set of cited sources $254 \times 197 \mathrm{~mm}(144 \times 144 \mathrm{DPI})$ 


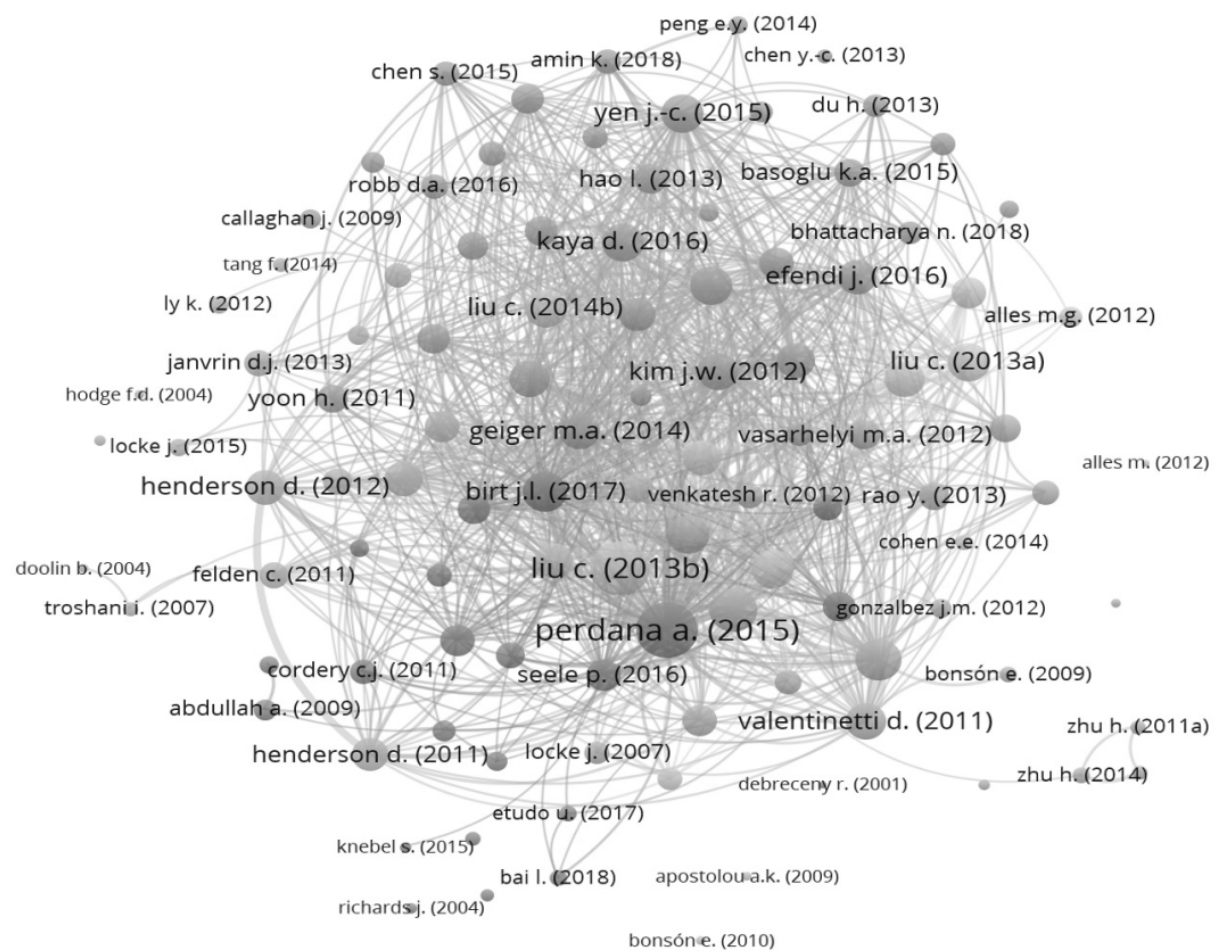

Network diagram of the bibliographic coupling of articles

$241 \times 185 \mathrm{~mm}(144 \times 144 \mathrm{DPI})$ 


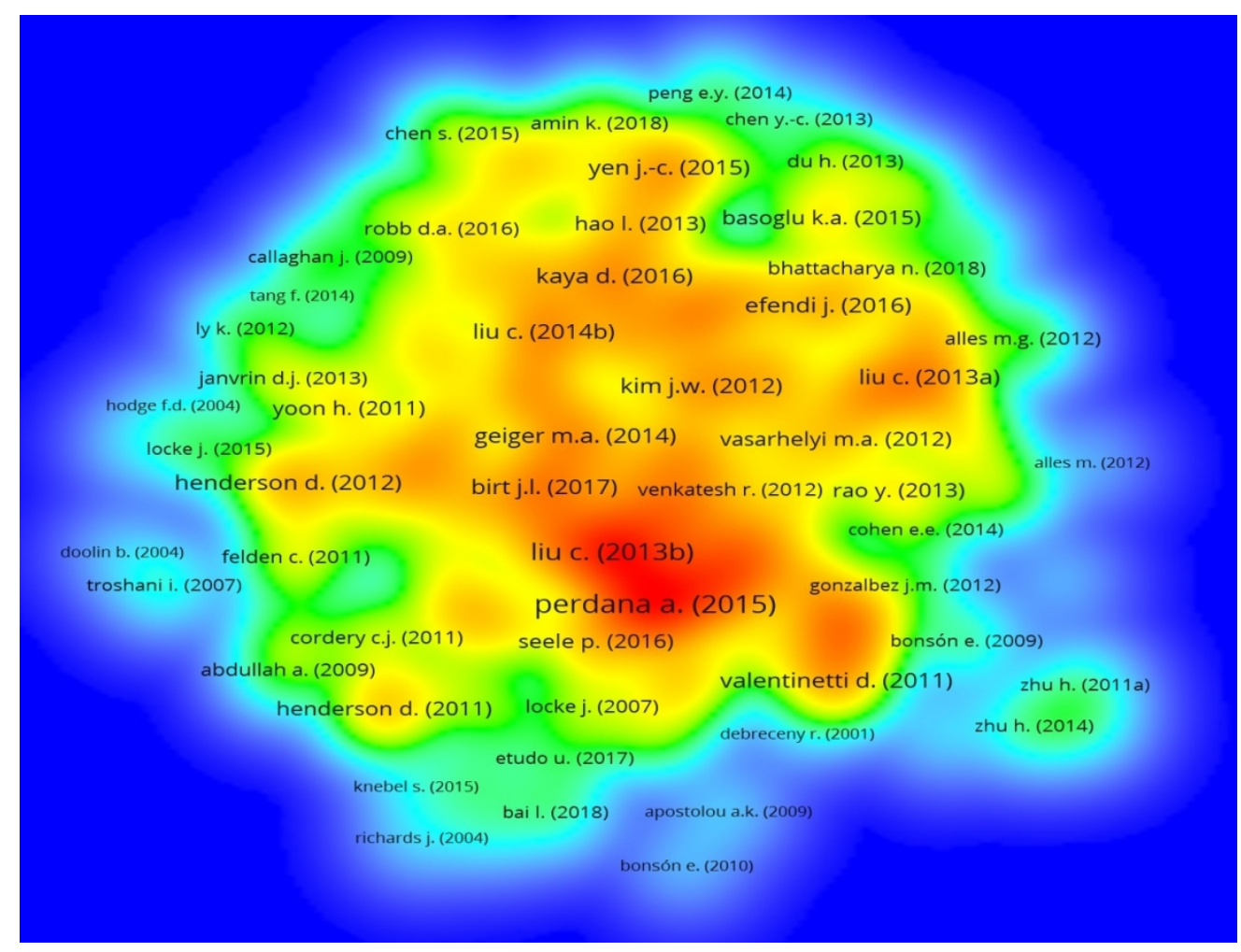

Density diagram of the bibliographic coupling of articles $251 \times 191 \mathrm{~mm}(144 \times 144 \mathrm{DPI})$ 
Journal of central banking the

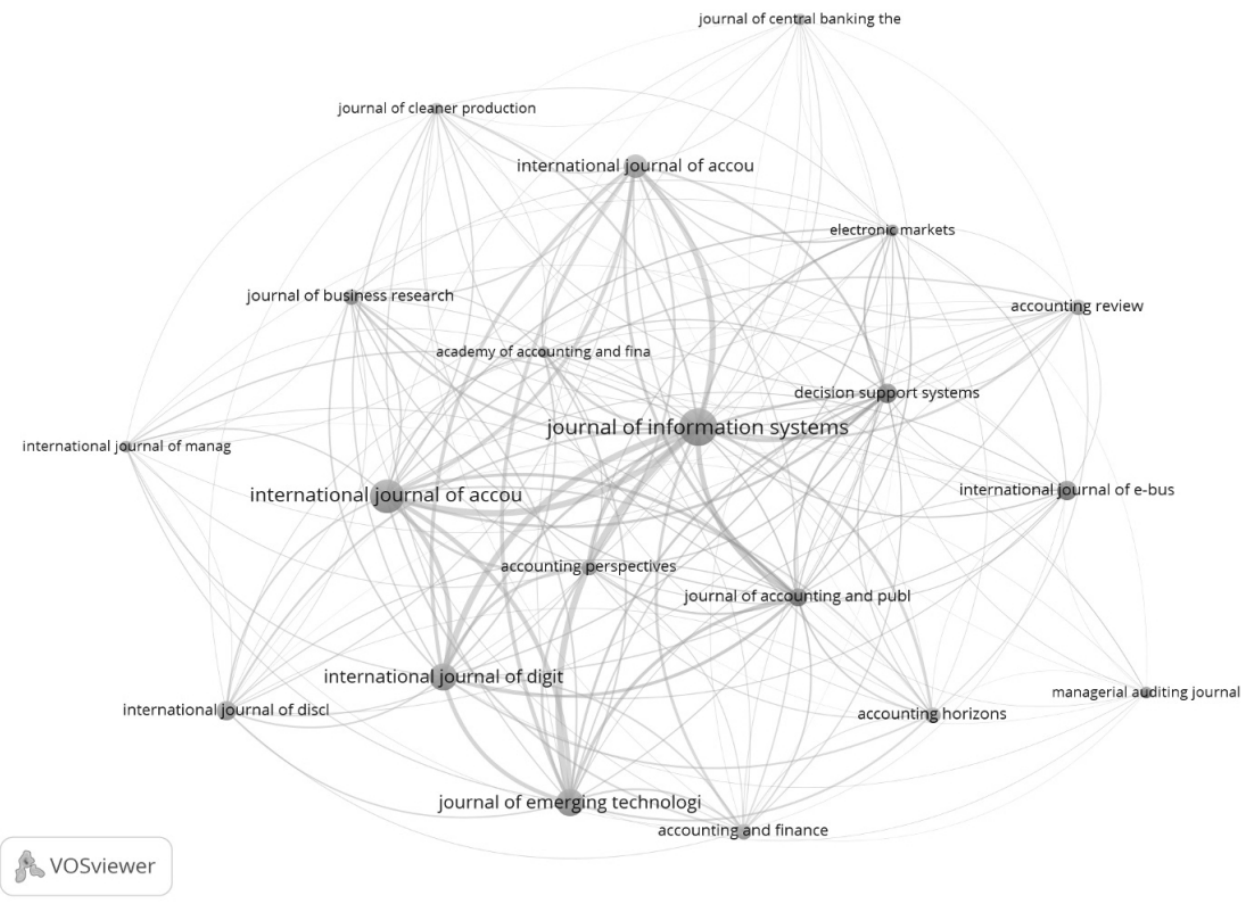

Network diagram of the bibliographic coupling of journals 


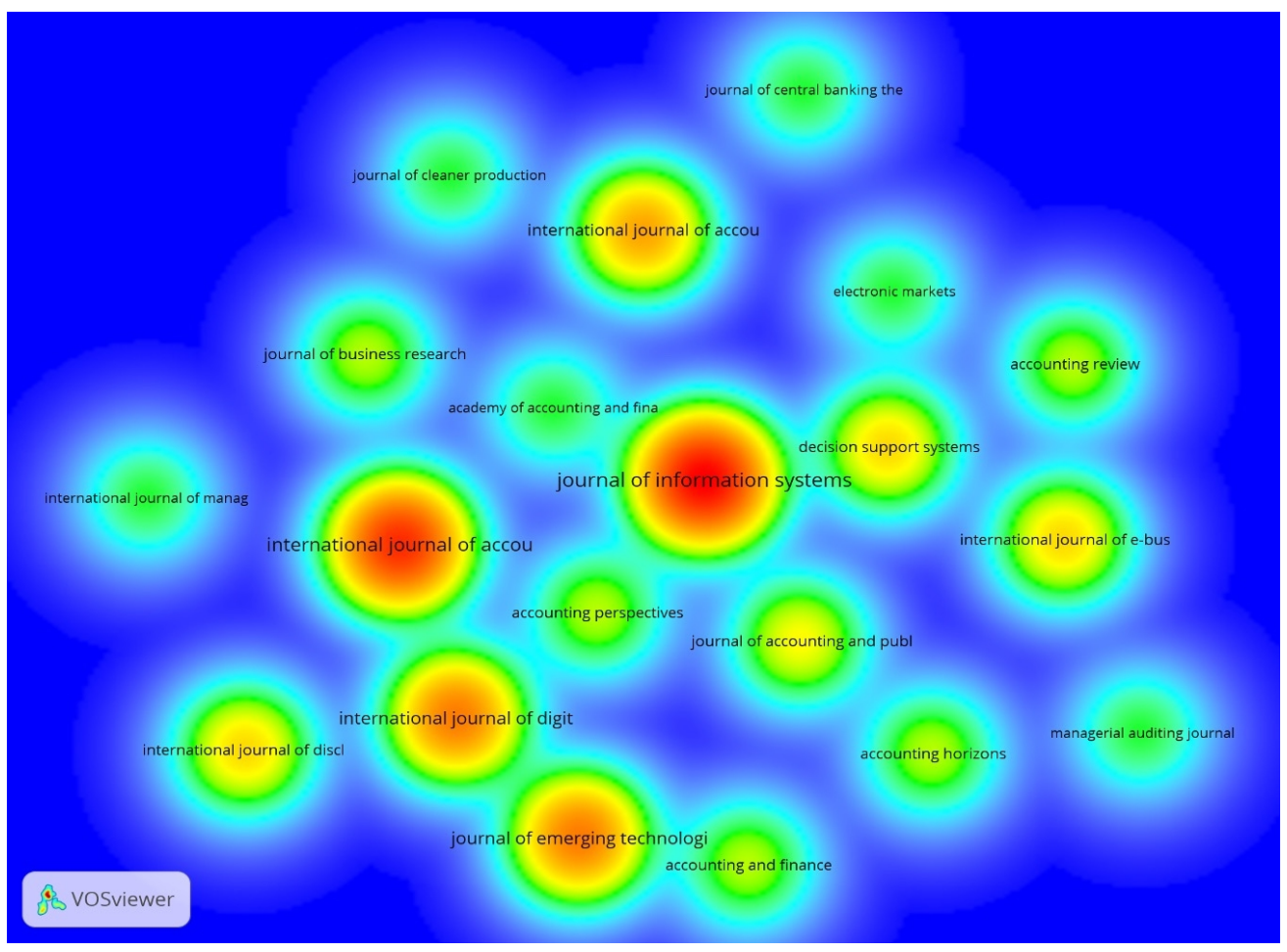

Density diagram of the bibliographic coupling of journals $237 \times 173 \mathrm{~mm}(144 \times 144$ DPI $)$ 


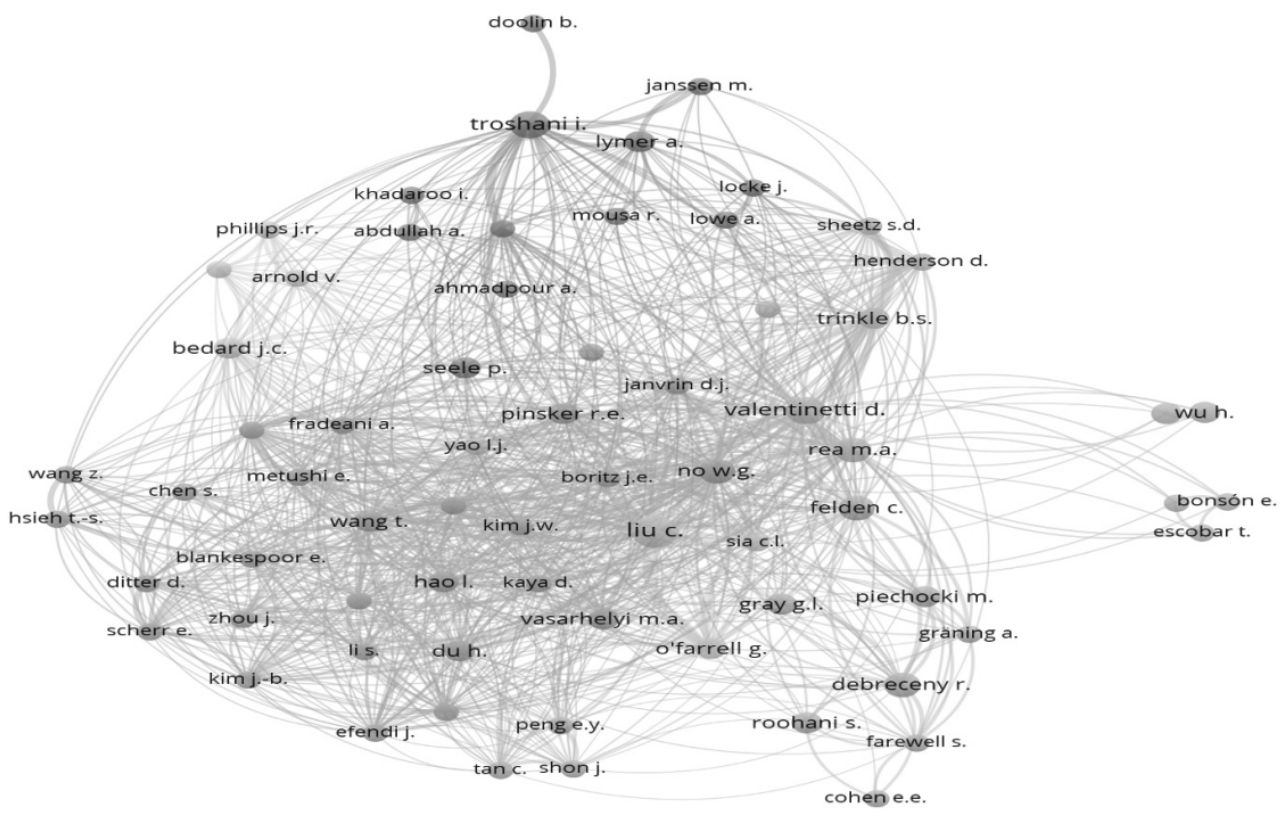

Network diagram of the bibliographic coupling of authors

$245 \times 159 m m(144 \times 144$ DPI $)$ 


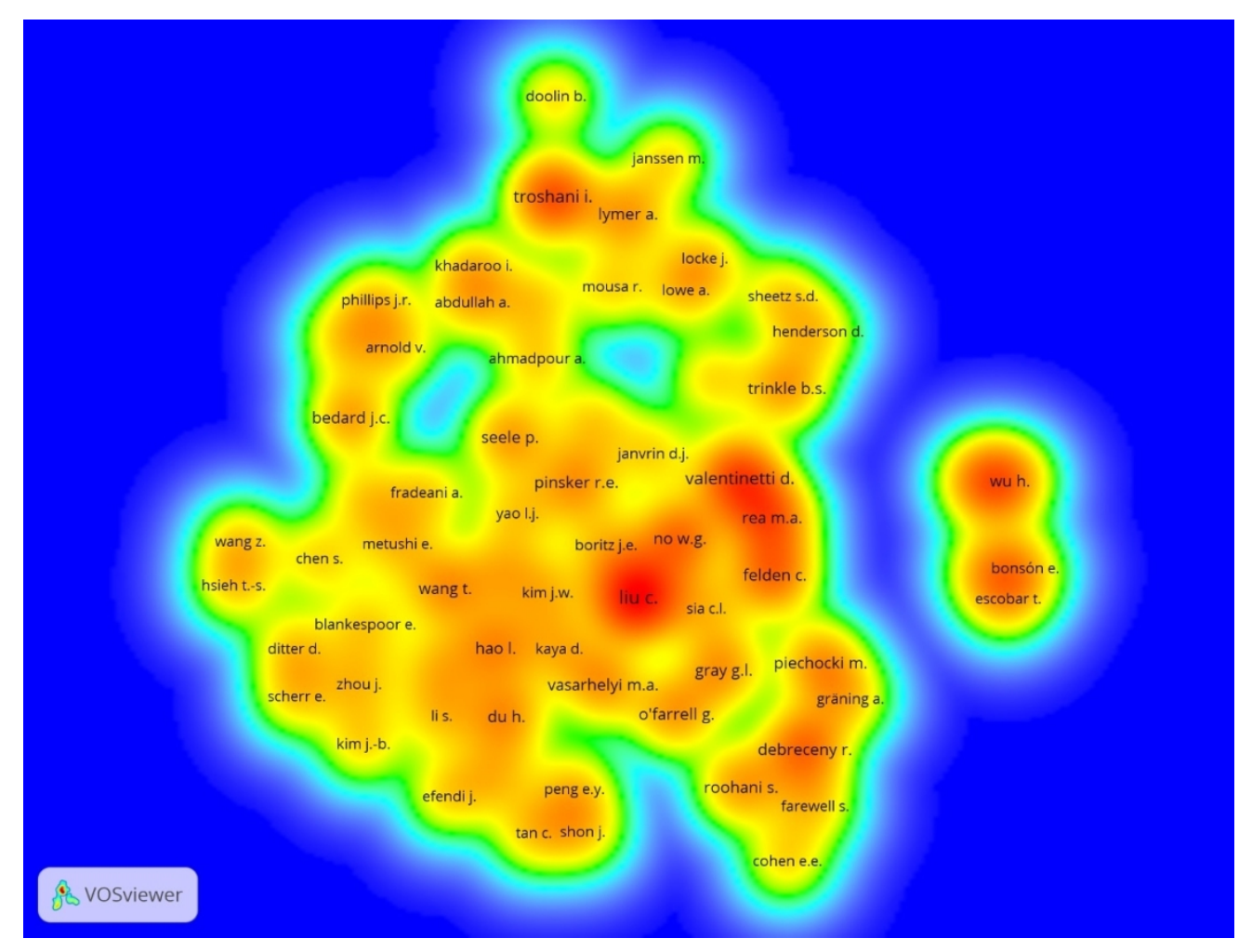

Density diagram of the bibliographic coupling of authors $246 \times 186 \mathrm{~mm}(144 \times 144$ DPI $)$ 


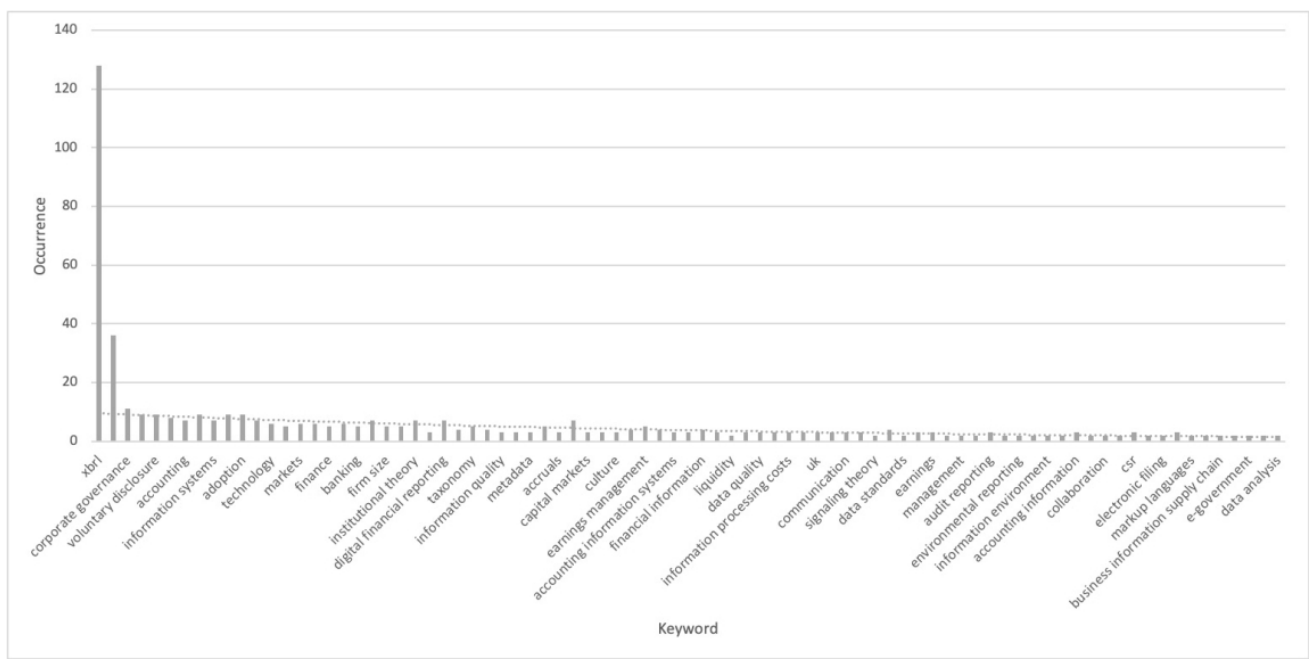

Occurrence of keywords

$271 \times 135 \mathrm{~mm}(144 \times 144 \mathrm{DPI})$ 


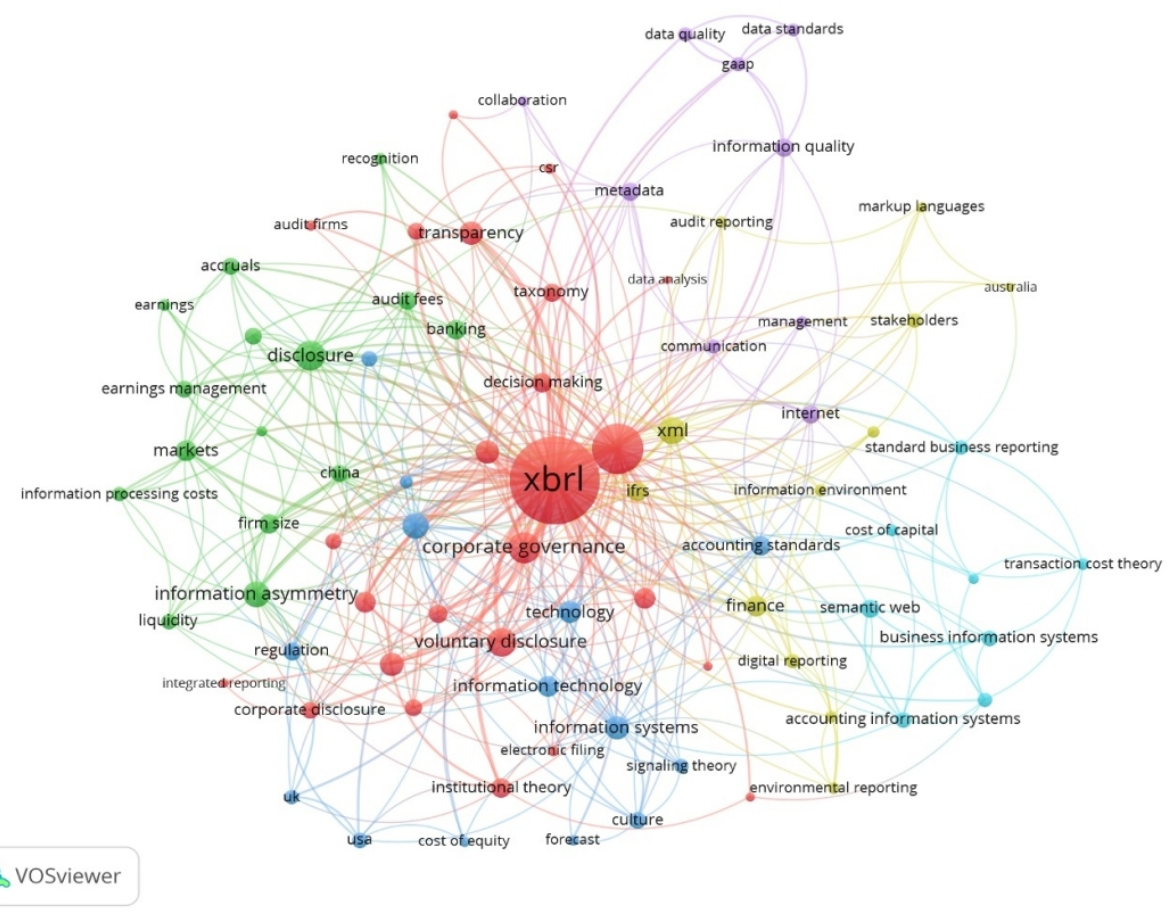

Network diagram of the co-occurrence of keywords 


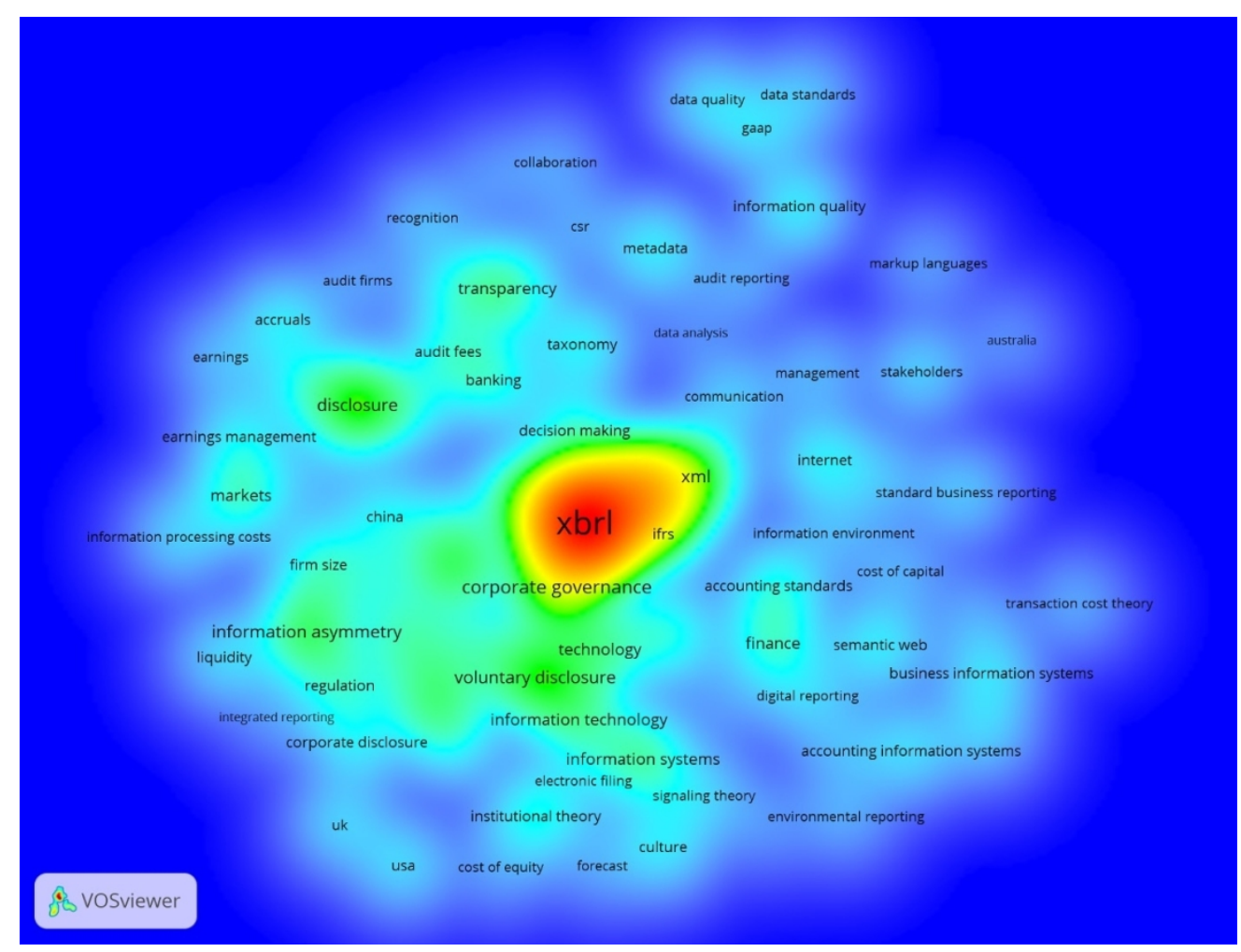

Density diagram of the co-occurrence of keywords $246 \times 187 \mathrm{~mm}(144 \times 144 \mathrm{DPI})$ 